\title{
Global use of water resources: a multiregional analysis of water use, water footprint and water trade balance
}

\author{
Iñaki Arto; Valeria Andreoni; José M. Rueda-Cantuche
}

\begin{abstract}
In this paper a multiregional input-output model is proposed and used to estimate time series trends for water use, water footprint and water trade balance. By using data provided by the World Input-Output Database, the water used in production, consumption and trade is quantified for 41 world regions between 1995 and 2008. Results show that global water use grew by $37.3 \%$, with China, India and Brazil contributing most to that increase. China and India, together with the EU-27, were also responsible for the largest water footprint variations. In terms of trade, the EU-27 was the largest water importer and China and India the main water exporters. The results provided in this paper offer an overview of the main countries' responsibility for the use of water resources. They provide a good starting point for international debates and policies on sustainable water use.
\end{abstract}

Keywords: Water use; Water footprint; Water trade balance; Multiregional input-output model; Time series data

\section{Introduction}

During the last century water use has been increasing at more than twice the rate of population growth, making water scarcity one of the most urgent challenges facing human society in the $21^{\text {st }}$ century (UNESCO WAPP, 2006). Water stress generated by pollution and climate change, a growing world population and an increasing water demand are some of the most important factors affecting the local and global availability of fresh water resources (Vorosmarty et al., 2000; Rosegrant et al., 2002).

Despite researchers and international organizations increasingly highlighting the global dimension of water changes, most governments still manage water resources from a national perspective, focusing on the use of water within national territories, and ignoring both the large-scale impacts generated by local water use and the global dimensions of water supply. For this reason the majority of water policies are unable to address the issue in an over-national perspective and plans for water policies moving beyond the regional borders are still lacking (Hoekstra, A.Y., 2011, Hoekstra et al., 2011). The lack of data and analysis able to identify countries' responsibility on water trade and consumption is one of the main element making difficult the design of effective water policies and the consequent agreement between countries. In the present context of globalization, where 
different world regions are ever more integrated into global markets, large volumes of water are implicitly traded between regions, extending water responsibilities far beyond national borders.

To better investigate the existing differences between water demand, water supply and the geographical distance between them, the concepts of water footprint and virtual water trade were elaborated in the 1990s, and, since then, an increasing number of studies have been carried out to quantify these parameters. The water footprint, originally proposed by Hoekstra and Hung (2002), in an analogy of the ecological footprint (Rees, 1992), originates from the concept of 'virtual water' proposed by Allan (1993), in which the water footprint of a nation is the total volume of fresh water used to produce the goods and services demanded by the population of the nation, wherever this water has been used. In a similar way, the virtual water trade refers to the water embedded in the products traded between countries (Hoekstra and Hung, 2002; Zimmer and Renault, 2003).

Based on these concepts, a large number of studies have quantified the water footprint of countries and the water embodied in products (Oki and Kanae, 2004; Hoekstra and Chapagain, 2007; Chapagain and Hoekstra, 2007, 2008; Chapagain et al., 2006; Chapagain and Orr, 2009; Hubacek et al., 2009; Zhang et al., 2011; Feng et al., 2012; Steen-Olsen et al., 2012). In spite of the global dimension of water changes, the majority of these studies involve only a local perspective, and very few researchers have focused on a global analysis (Hoekstra and Hung, 2002; Hoekstra and Chapagain, 2007). Recently, Hoekstra and Mekonnen (2012) presented the first global estimation of water used and traded between countries. However, as their work covered an annual average for the period 1996-2005, the results do not show global water changes over time. Steen-Olsen et al. (2012) use a global model to estimate the water consumption and the (blue) water footprint of the EU-27 but also for one single year (2004). More recently, Roson et al. (2015) use a global model and the World Input-Output Database (WIOD) to decompose the change in the water footprint. In this paper we go a step beyond and provide, for the first time, complete time series data for global water use, ${ }^{1}$ water footprint (including results by consumption category) and water trade balance for the period 1995-2008. By using a multiregional input-output model and data from the WIOD, we provide water estimations for 40 regions: the 27 Member States of the European Union (EU-27), Australia, Brazil, Canada, China, India, Indonesia, Japan, South Korea, Mexico, Russia, Taiwan, Turkey, and the United States, and for the Rest of the World (RoW) as an aggregated region. The time series data provided in this paper are essential information both for the scientific community and for the policy arena. By estimating the water use, the water footprint and the water trade balance that took place at a global level for more than a decade, this paper supplies key information to aid investigation into key drivers in the use of water, to analyze the water dependency of countries, to asses country's responsibilities in terms of hydric stress and scarcity from a global perspective, to investigate the impacts of international trade and, ultimately, to help plan policies for a global sustainable water strategy.

\footnotetext{
${ }^{1}$ Note that here the term water use refers to the total amount of water used by the different economic activities and include both the portion of water not returned to the original source (i.e. water consumption) and the volume of water returned.
} 
The paper is structured as follows. Section 2 presents the database and explains the multiregional input-output method used to quantify the water use, the water footprint and the water trade balance. Section 3 summarizes the disaggregated results for water use, water footprint and water trade balance. Section 4 concludes. Additional data and tables are reported in the appendix.

\section{Data and Method}

\subsection{Data}

The World Input-Output Database is composed of a set of harmonized supply, use and symmetric multi-regional I-O tables reported both at current and previous year prices, and disaggregated between 35 industries, 59 products and 5 categories of final demand. The time period covered is 1995 to $2009,{ }^{2}$ and it includes data for 40 countries plus the Rest of the World (RoW) as an aggregated region. The WIOD also includes socio-economic and environmental satellite accounts for energy, emissions, water, land and materials.

The water data provided in the WIOD are used in this paper to calculate, for the first time, the water use, the water footprint and the water trade balance for all the countries reported in the database (for further information see Timmer et al., 2012). From a methodological point of view, water data in the WIOD are estimated by using the concepts of blue, green and grey water as proposed by Hoekstra et al. (2011). In addition, the agricultural water use of the WIOD has been estimated based on data on crop production and livestock provided from FAOSTAT and based on the crop and livestock water intensities proposed by Mekonnen and Hoekstra (2010a; 2010b). Similarly, the water evaporated from artificial reservoirs to produce electricity has been calculated using the world average water use per unit of electricity as estimated by Mekonnen and Hoekstra (2011b) and the hydropower generation from the IEA. The use of water in other economic sectors has been calculated by using the total water use in industry as reported by Mekonnen and Hoekstra (2011a), the shares of water use by industry in the EXIOPOL database, and the sectoral gross output at constant prices from the WIOD. Finally, water use by households is estimated on the basis of the average domestic water supply from Mekonnen and Hoekstra (2011a) and population data from the United Nations.

\subsection{Method}

Two different approaches have generally been used in literature to quantify the water footprint and virtual water trade of countries, namely: the bottom-up approach and the top-down approach (see Feng et al., 2011 and Antonelli et al., 2012 for a detailed description and discussion of differences). In this paper we use a top-down approach using a Multi-Regional Input-Output (MRIO) model.

MRIO models have been widely used to calculate footprints and to analyze the environmental consequences of trade (Turner et al., 2007; Wiedmann et al., 2007; Wiedmann, 2009; Wiedmann

\footnotetext{
${ }^{2}$ As the 2009 figures are preliminary estimates, the time span used in this paper has been limited to the period 19952008 .
} 
and Barrett, 2011). Although these models have generally been used to estimate $\mathrm{CO}_{2}$ emissions, some applications exist for calculating the water footprint and the virtual water trade of specific countries (Feng et al., 2011, Steen-Olsen et al., 2012). A methodology is described in this paper for the case of 3 regions (1, 2 and 3) with $n$ sectors, and 1 type of water but it could be applied to any number of regions and sectors. In this paper, the MRIO model will be applied to 41 regions (40 countries plus the rest of the world considered as an aggregated region), 35 industries, 3 final demand categories, and 3 types of water.

The starting point for the model is the MRIO table. This table describes the flows of goods between sectors and countries, and the use of goods by final users. We can distinguish three main components in the MRIO table:

$$
Z=\left[\begin{array}{lll}
Z^{11} & Z^{12} & Z^{12} \\
Z^{21} & Z^{22} & Z^{23} \\
Z^{31} & Z^{32} & Z^{33}
\end{array}\right], \mathbf{f}=\left[\begin{array}{l}
\mathbf{f}^{1} \\
\mathbf{f}^{2} \\
\mathbf{f}^{3}
\end{array}\right]=\left[\begin{array}{l}
\mathbf{f}^{11}+\mathbf{f}^{12}+\mathbf{f}^{13} \\
\mathbf{f}^{21}+\mathbf{f}^{22}+\mathbf{f}^{23} \\
\mathbf{f}^{31}+\mathbf{f}^{32}+\mathbf{f}^{33}
\end{array}\right], \mathbf{x}=\left[\begin{array}{c}
\mathbf{x}^{1} \\
\mathbf{x}^{2} \\
\mathbf{x}^{3}
\end{array}\right]
$$

where $\mathbf{Z}^{r s}$ is the intermediate matrix with sectoral deliveries from country $r$ to country $s$; $\mathbf{f}^{r s}$ is the column vector of the final demand of country $s$ (including household consumption, government consumption, and investment) for goods produced by country $r$; and $\mathbf{x}^{r}$ is the column vector of gross output for country $r$. The relationship between $\mathbf{x}, \mathbf{Z}$ and $\mathbf{f}$ is defined by the accounting equation $\mathbf{x}=\mathbf{Z i}+\mathbf{f}$, where $\mathbf{i}$ is the column summation vector consisting of ones.

Furthermore, it is assumed that the MRIO table is extended to include a vector for sectoral water use by country $\mathbf{w}$, and a vector for household water use by country $\mathbf{h}$ :

$$
\mathbf{w}=\left[\begin{array}{c}
\mathbf{w}^{1} \\
\mathbf{w}^{2} \\
\mathbf{w}^{3}
\end{array}\right]=\left[\begin{array}{c}
\mathbf{w b}^{1}+\mathbf{w g}^{1}+\mathbf{w r}^{1} \\
\mathbf{w b}^{2}+\mathbf{w g}^{2}+\mathbf{w r}^{2} \\
\mathbf{w b} \mathbf{b}^{3}+\mathbf{w g}^{3}+\mathbf{w r}^{3}
\end{array}\right], \mathbf{h}=\left[\begin{array}{c}
h^{1} \\
h^{2} \\
h^{3}
\end{array}\right]=\left[\begin{array}{c}
h b^{1}+h r^{1} \\
h b^{2}+h r^{2} \\
h b^{3}+h r^{3}
\end{array}\right]
$$

where $\mathbf{w b}^{\mathbf{r}}, \mathbf{w g}^{\mathbf{r}}$ and $\mathbf{w r}^{\mathbf{r}}$ denote the use ${ }^{3}$ of blue, green and grey water by the economic sectors of region $r$ respectively, and $h b^{\mathrm{r}}$ and $h r^{\mathrm{r}}$ are the use of blue and grey water by households in region $r$. Therefore, the total use of water in region 1 would be given by the sum of the sectoral water use plus the direct water use by households, as reported in equation [1]:

$$
\text { wuse }^{1}=\left(\mathbf{w}^{1}\right)^{\prime} \mathbf{i}+h^{1}
$$

\footnotetext{
${ }^{3}$ Note that the water use covers the water used for producing goods absorbed by both the domestic and the foreign final demands.
} 
The input coefficient matrix for the whole system is defined as $\mathbf{A}=\mathbf{Z}(\hat{\mathbf{x}})^{-1}$, where $(\hat{\mathbf{x}})$ is a diagonal matrix with the values of vector $\mathbf{x}$ along its diagonal and zero elsewhere. Thus, the accounting equation can now be written as the standard input-output model: $\mathbf{x}=\mathbf{A x}+\mathbf{f}$. The last is the basic equation of the standard input-output model. For an arbitrary final demand vector $\mathbf{f}$, the solution to the model is given by $\mathbf{x}=\mathbf{L} \mathbf{f}$, where $\mathbf{L} \equiv(\mathbf{I}-\mathbf{A})^{-1}$ is the Leontief inverse.

The water coefficients vector, $\mathbf{v}=(\hat{\mathbf{x}})^{-1} \mathbf{w}$, gives the amount of water per unit of output. Hence, the amount of water required for the production of goods in order to satisfy total final demand $\mathbf{f}$ is given by equation [2]:

$$
\mathbf{w}=\hat{\mathbf{v}} \mathbf{x}=\hat{\mathbf{v}} \mathbf{L f}
$$

We can write [2] in its partitioned form as reported in equation [3]:

$$
\left[\begin{array}{c}
\mathbf{w}^{1} \\
\mathbf{w}^{2} \\
\mathbf{w}^{3}
\end{array}\right]=\left[\begin{array}{ccc}
\hat{\mathbf{v}}^{1} & \mathbf{0} & \mathbf{0} \\
\mathbf{0} & \hat{\mathbf{v}}^{2} & \mathbf{0} \\
\mathbf{0} & \mathbf{0} & \hat{\mathbf{v}}^{3}
\end{array}\right]\left[\begin{array}{lll}
\mathbf{L}^{11} & \mathbf{L}^{12} & \mathbf{L}^{13} \\
\mathbf{L}^{21} & \mathbf{L}^{22} & \mathbf{L}^{23} \\
\mathbf{L}^{31} & \mathbf{L}^{32} & \mathbf{L}^{33}
\end{array}\right]\left[\begin{array}{l}
\mathbf{f}^{11}+\mathbf{f}^{12}+\mathbf{f}^{13} \\
\mathbf{f}^{21}+\mathbf{f}^{22}+\mathbf{f}^{23} \\
\mathbf{f}^{31}+\mathbf{f}^{32}+\mathbf{f}^{33}
\end{array}\right]
$$

From [3] we can calculate the water footprint $\mathbf{w f p}^{1}$, and the water embodied in the exports $\mathbf{w e x p}^{1}$ and imports wimp $^{1}$ of region 1 , as reported in equations [4], [5] and [6]:

$$
\begin{aligned}
& \operatorname{wfp}^{1}=\hat{\mathbf{v}} \mathbf{L} g^{1}+h^{1} \\
& \operatorname{wexp}^{1}=\hat{\mathbf{v}}^{1} \mathbf{L}^{11}\left(\mathbf{f}^{12}+\mathbf{f}^{13}\right)+\hat{\mathbf{v}}^{1} \mathbf{L}^{12} \mathbf{f}^{2}+\hat{\mathbf{v}}^{1} \mathbf{L}^{13} \mathbf{f}^{3} \\
& \operatorname{wimp}^{1}=\left(\hat{\mathbf{v}}^{2} \mathbf{L}^{21}+\hat{\mathbf{v}}^{3} \mathbf{L}^{31}\right) \mathbf{f}^{11}+\left(\hat{\mathbf{v}}^{1} \mathbf{L}^{12}+\hat{\mathbf{v}}^{2} \mathbf{L}^{22}+\hat{\mathbf{v}}^{3} \mathbf{L}^{32}\right) \mathbf{f}^{21}+\left(\hat{\mathbf{v}}^{1} \mathbf{L}^{13}+\hat{\mathbf{v}}^{2} \mathbf{L}^{23}+\hat{\mathbf{v}}^{3} \mathbf{L}^{33}\right) \mathbf{f}^{31}
\end{aligned}
$$

where $\mathbf{g}^{1}$ is a column vector that represents the domestic final demand of country 1 :

$$
\mathbf{g}^{1}=\left[\begin{array}{l}
\mathbf{f}^{11} \\
\mathbf{f}^{21} \\
\mathbf{f}^{31}
\end{array}\right]
$$

The difference between the water embodied in exports and imports gives the water trade balance $\mathbf{w t b}^{1}$ as shown in equation [7]:

$$
\text { wtb }^{1}=\text { wexp }^{1}-\text { wimp }^{1}
$$

A deficit/surplus in the water trade balance indicates that the water embodied in imports is greater/less than the water exported. Moreover, a deficit in the water trade balance indicates that, in 
the absence of trade, ceteris paribus, the current domestic water use of a country would not be able to satisfy its domestic final demand (the contrary applies to a surplus). In this regard, it can be demonstrated that the total water footprint of a country is identical to its water use plus the water embedded in its imports minus the water embedded in its exports. In other words, as reported in equation [8], the total water footprint of a country is identical to its total water use minus its water trade balance:

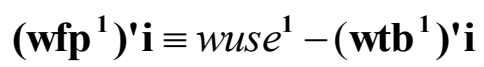

From equations [1] and [7] we can define the domestic coverage ratio $w d c r^{1}$ of equation [9] as the share of the water footprint of region 1 that is covered by its water use:

$$
w d c r^{1}=\frac{w u s e^{1}}{\left(\mathbf{w f p}^{1}\right)^{\prime} \mathbf{i}}
$$

Similarly, it is possible to calculate the virtual water embodied in the trade and the water footprint of the other two regions.

Finally, the water footprint can be split into the different components of the final demand (private consumption, government consumption and investment) and water types (blue, green and grey).

Moreover, private consumption can be further disaggregated according to consumption categories as follows. The first step consists of allocating part of the impacts embodied in transport and wholesale and retail trade margins to the sectors that incorporate these margins. To this end, country-specific information on margins paid and received from EUROSTAT for the EU-27 countries and the EU-27 structures for non-EU-27 countries were used. Furthermore, the household footprint by consumption category can be obtained by distributing the footprint calculated in the previous step to COICOP consumption categories, using bridge matrices created by the Joint Research Centre, Institute for Prospective Technological Studies of the European Commission.

\section{Results}

The multiregional input-output model presented above and the WIOD have been used in this paper to calculate the water use, the water footprint and the water trade balance for 40 countries and for the Rest of the World for the period 1995-2008. Section 3.1 and Section 3.2 summarizes the results for water use and water footprint. Section 3.3 summarizes the water trade balance, together with the domestic coverage ratio. Disaggregated data for the 40 countries plus the rest of the world together with complete time series analysis are reported in the appendix. Further results can also be found in (Arto et al., 2012a, b)

\subsection{Water use of countries}


According to equation [1] of the model, the water use is calculated as the sum of the blue, the green and the grey water directly used within a country by economic sectors plus the blue and grey water directly used by households. The main results show that:

- According to data reported in Table A.1 of the appendix, between 1995 and 2008 the global water use increase by more than $37.3 \%$, corresponding to $2.5 \%$ annual growth rate. China, India and Brazil were the countries that performed the largest absolute and percentage variations. Japan has been the only non EU-27 country to reduce the water use.

- In Figure 1, the per capita water use is reported together with the population for the year 2008. At global level, the average per capita water use is $1,780 \mathrm{~m}^{3} / \mathrm{cap}$ (red line in Figure 1). However, large differences exist in the distribution of water use across countries. In 2008, $14.1 \%$ of the world population with a per capita water use above the world average was responsible for $29.4 \%$ of the total water use. Meanwhile, $85.9 \%$ of the population, with a water use per capita below the world average, used $70.6 \%$ of the global water use.

- Canada, Australia, Russia, Brazil and United States are the countries with the higher per capita water use. The size of the agricultural sector and/or the volume of exports of agricultural products in relation to the population are key factors in these figures. The most populates world regions, i.e. China and India have a per capita water use that run below the world average.

- According to data reported in Table A.2. of the appendix, between 1995 and 2008 the global water use per capita increase by $(+16.6 \%)$. Russia, China and Brazil had the largest percentage and absolute variations. Australia, Turkey, Japan and South Korea were the only countries to reduce the per capita water use. 
Fig. 1. Water Use per capita ( $\left.\mathrm{m}^{3} / \mathrm{cap}\right)$ and population (million) (2008)

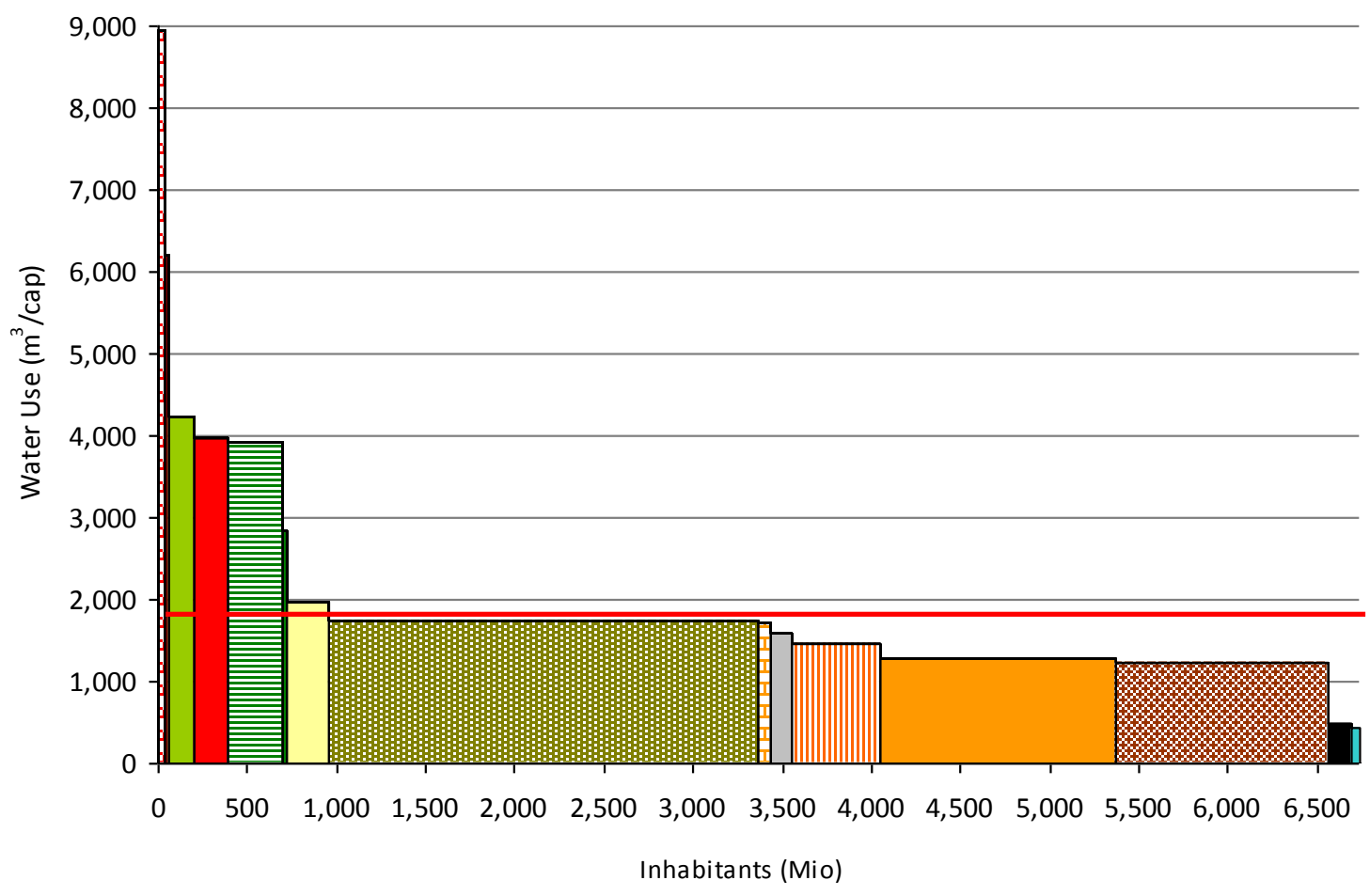

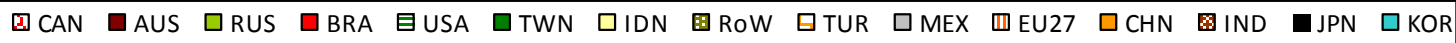

AUS: Australia; BRA: Brazil; CAN: Canada; CHN: China; EU-27: European Union; IDN: Indonesia; IND: India; JPN: Japan; KOR: South Korea; MEX: Mexico; RoW: Rest of the World; RUS: Russia; TWN: Taiwan; TUR: Turkey; USA: United States of America.

Red line: world average $\left(1,739 \mathrm{~m}^{3} / \mathrm{cap}\right)$.

\subsection{Water footprint of countries}

Water footprint is defined as the water used both domestically and abroad to produce the goods and services consumed in a country plus the water used directly by households within the countries (Hoekstra and Hung, 2002). By using equation [4], reported in the previous paragraph, we calculated the water footprint of countries together with the variations across the period. The main results show that:

- According to data reported in Table A.3 of the appendix, between 1995 and 2008, the global water footprint increased by more $37.3 \%{ }^{4}$. China was the country with the largest increase, followed by the EU-27, India and United States. Japan has been the only non EU-27 country to reduce the water footprint.

- Within the EU-27, all Member States, with the exception of Bulgaria, increased their water footprint. Spain and the United Kingdom had the largest variation.

\footnotetext{
${ }^{4}$ The total water footprint is equal to the total water use. Since the water embedded in the goods and services consumed worldwide must be equal to the water used for producing those products, the total water use at global level has to equal the total water footprint.
} 
- In per capita terms, the average water footprint amounted to $1,780 \mathrm{~m}^{3} / \mathrm{cap}$ in 2008 (red line in Figure 2). However, as in the case of water use, many differences exists between countries. In 2008, 26\% of the world population, with a water footprint above the world average, accounted for $43 \%$ of the global water footprint, while the $74 \%$ of the population that showed a water footprint below the world average consumed $57 \%$ of the water resources. China, India and the countries included in the Rest of the World region show a per capita water footprint running below the world average.

- Between 1995 and 2008 the global water footprint per capita grew by 17\%, with an annual growth rate of $1.2 \%$. Russia is the country with the largest increase, followed by China, EU27 and Indonesia. Japan was the only country to reduce its per capita value. Table A.4 of the appendix summarizes the absolute and the percentage variations disaggregated between countries and years.

\section{Fig. 2. Water footprint per capita (m³/cap) and population (million) (2008)}

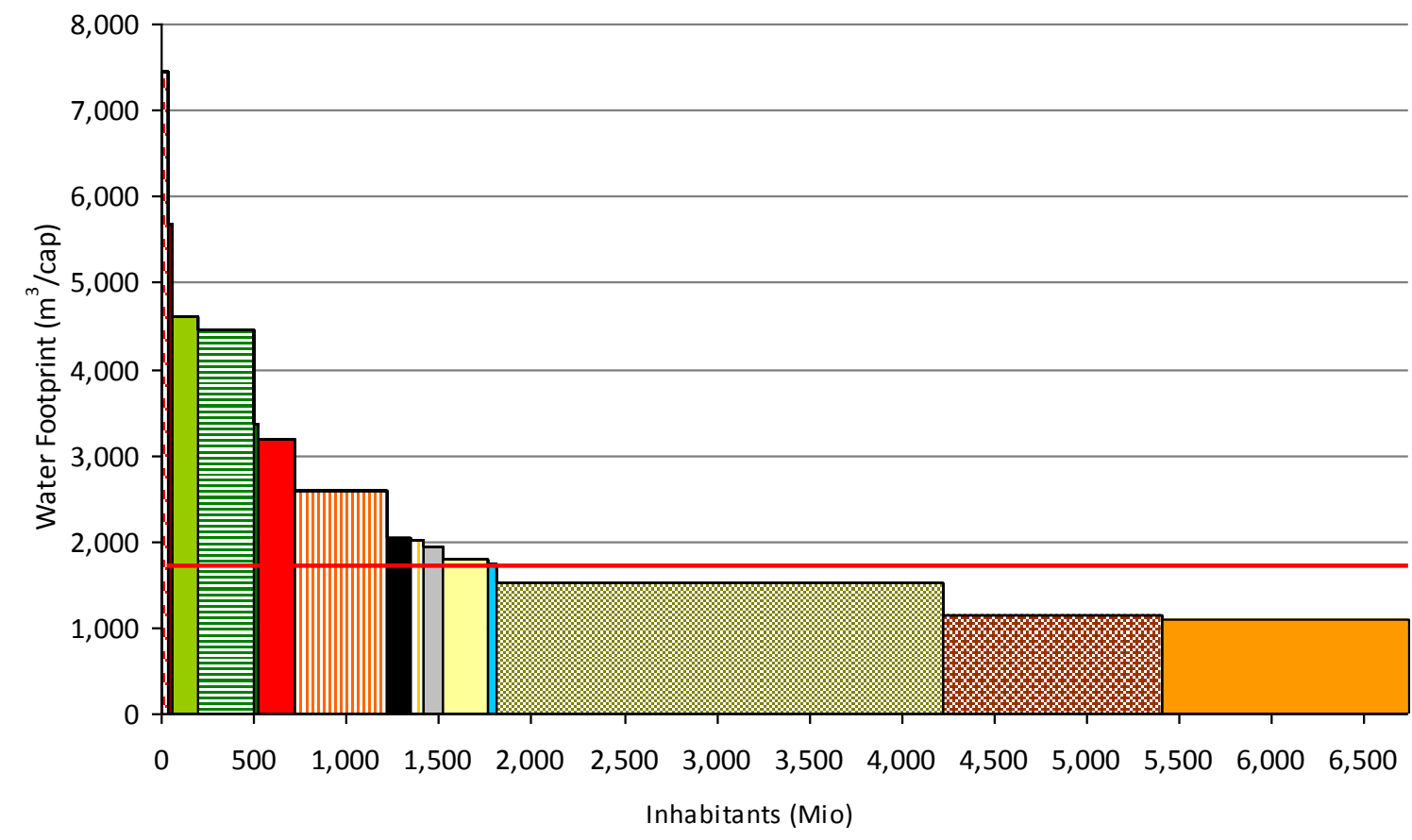

$\square$ CAN $\square$ AUS $\square$ RUS GUSA $\square$ TWN $\square$ BRA $\square$ EU27 $\square$ JPN $\square$ TUR $\square$ MEX $\square I D N \quad \square$ KOR $\square$ RoW $\quad$ INDD $\square$ CHN

AUS: Australia; BRA: Brazil; CAN: Canada; CHN: China; EU-27: European Union; IDN: Indonesia; IND: India; JPN: Japan; KOR: South Korea; MEX: Mexico; RoW: Rest of the World; RUS: Russia; TWN: Taiwan; TUR: Turkey; USA: United States of America.

Red line: world average $\left(1,780 \mathrm{~m}^{3} / \mathrm{cap}\right)$.

To investigate the main factors influencing the water footprint of the different countries considered in this paper, a disaggregated analysis has been performed for final demand categories, including eight categories of private consumption plus the direct use of water by households, government consumption and investment. According to data reported in Figure 3: 
- Food and drinks have the largest share of water footprint in all the countries analyzed except China and Canada. In the case of China this result is due to the high contribution of the water footprint of investment (29\% of the total water footprint compared to $11 \%$ at the global level). In the case of Canada, the lower contribution of food and drinks is linked to the high share of housing, fuel and power (23\% of the total water footprint compared to $6 \%$ at the global level), resulting from the high share of hydropower generation in the Canadian electricity mix.

- The share of the water footprint linked to the private expenditure in recreation, restaurants and hotels is over $10 \%$ in all countries and represents $15 \%$ of the world's water footprint.

- At the global level, $11 \%$ of the water footprint is due to investment and $4 \%$ is due to government consumption.

- The contribution of the private expenditure in the housing, fuel \& power category to the global water footprint is close to $6 \%$, with higher shares in countries in which hydropower represents a relevant share of the electricity mix like in Brazil or Canada.

Fig. 3. Water footprint per capita by final demand category (2008)

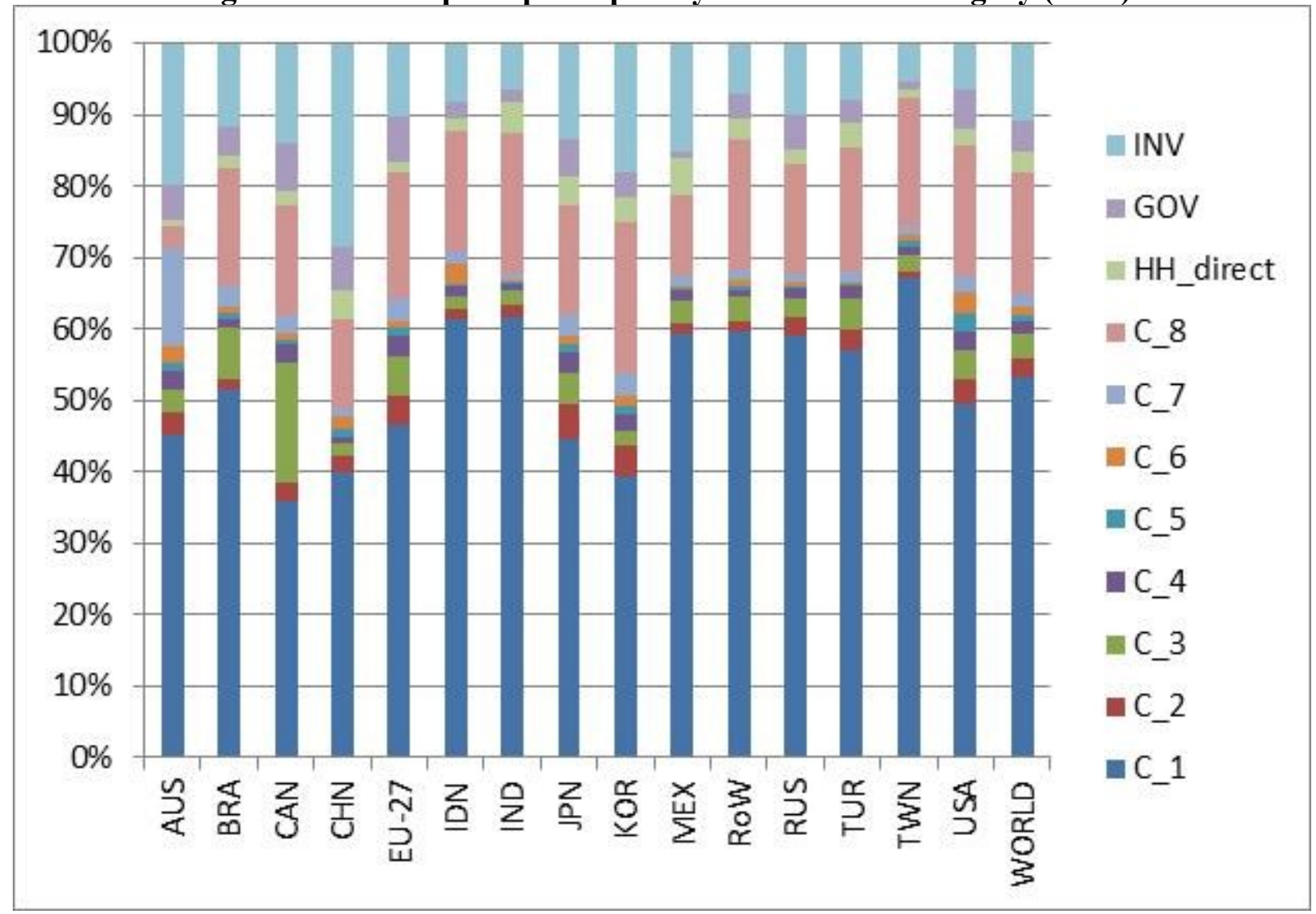


AUS: Australia; BRA: Brazil; CAN: Canada; CHN: China; EU-27: European Union; IDN: Indonesia; IND: India; JPN: Japan; KOR: South Korea; MEX: Mexico; RoW: Rest of the World; RUS: Russia; TWN: Taiwan; TUR: Turkey; USA: United States of America.

C_1: Food \& drinks, C_2: Clothing \& footwear, C_3: Housing, fuel \& power, C_4: Household goods \& services, C_5: Health \& education, C_6: Transport \& communications, C_7: Recreation, restaurants \& hotels, C_8: Miscellaneous goods \& services, HH_direct: Households direct, GOV: Government, INV: Investment.

\subsection{Water trade balance}

The differences that exist between the countries' value of water footprint and water use are related to the trade of water embodied in products. For instance, China accounts for $14.1 \%$ of the global water use. However, when analyzing the data for the water footprint, the Chinese percentage account for $12.2 \%$. The reason is related to the fact that the water used in China to produce goods and services is higher than the quantity of water consumed by the Chinese population. Similarly, India, Brazil, Japan and Taiwan also have a water footprint value lower than their country water use. The opposite can be observed in countries like Australia, Canada, South Korea, Mexico, Russia, Turkey, the United States and the EU-27, where the water footprint is higher than the water use. This means that a part of their domestic water needs is satisfied with foreign resources embedded into products imported by trade. This also indicates potential for limited resilience of the virtual water network with respect to the possible decision of one of these suppliers to stop or reduce its exports; thus, the importing countries are left with limited options for the diversification of their virtual water providers (Carr et al., 2013).

In order to quantify the main differences existing between water use and consumption, the equations [5], [6] and [7], reported in the previous section, allow to quantify the water deficit (surplus) of a country. Defined as water trade balance, it is calculated as the difference between the water used to produce the goods and services exported and consumed abroad and the water used to produce the goods and services imported and consumed in a country. As summarized in the methodology section, the water footprint of a country equals the country's water use minus its virtual water trade balance. Therefore, the virtual water trade balance can be used to explain the differences between the water use and footprint highlighted in the previous section. In this regard, the virtual water trade results reported in this section will be oriented to highlight the water coverage ratio of countries and the origin and destination of bilateral water flows.

\section{Water coverage ratio:}

- According to Table A.5, in the year 2008, Japan, South Korea, the EU-27, Mexico, Taiwan, Turkey, the United States, and Russia all had a domestic coverage ratio below $100 \%$. This means that, in the absence of trade, ceteris paribus, these countries would be unable to fully satisfy the domestic water demand with the current volume of water used. 
- Australia, Brazil, Canada, China, India, Indonesia and the Rest of the World are the only regions with a coverage ratio over $100 \%$. This means that these countries are net water exporters.

Water trade flows:

- According to data reported in Figure 4, that summarize the water imports, exports and the virtual water trade balance between 1995 and 2008, the EU-27, Japan and the United States were the countries with the highest water trade deficit. The EU-27 and the Unites States are also the countries with the largest water deficit increase. Japan is the only country to reduce it.

- The Rest of the World (RoW), China, Brazil, Canada, India and Indonesia were the main net water exporters

- Based on data reported on Table A.7, that shows the virtual trade flows between countries for the year $2008^{5}$, the Rest of the World (RoW) and China were the main origin of imports for almost all the countries considered in this paper, followed by the USA and Brazil.

- The EU-27 is a net virtual water importer from all the regions except Japan and South Korea. These two countries are the only ones with a virtual water deficit with all the regions considered in this paper.

Fig. 4: Water import, export and water trade balance $\left(\mathrm{km}^{3}\right)$

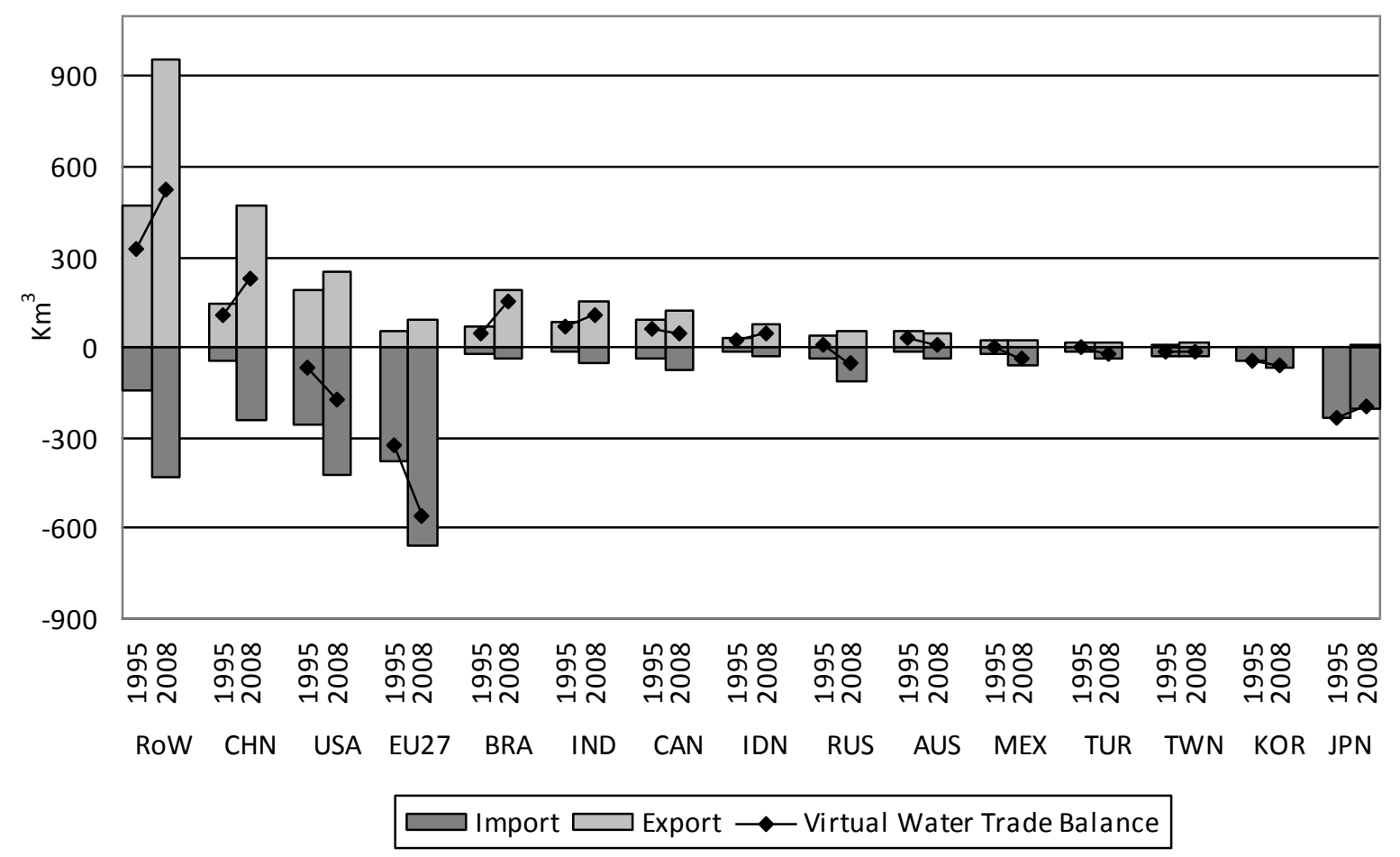

\footnotetext{
${ }^{5}$ The exports by destination country are shown row-wise, and the imports by origin column-wise
} 
AUS: Australia; BRA: Brazil; CAN: Canada; CHN: China; EU-27: European Union; IDN: Indonesia; IND: India; JPN: Japan; KOR: South Korea; MEX: Mexico; RoW: Rest of the World; RUS: Russia; TWN: Taiwan; TUR: Turkey; USA: United States of America.

\section{Limitations}

However, we have to highlight some possible limitations derived from the dataset. One of the main shortcomings of using the WIOD for the analysis of water issues is the sector aggregation of the database. Although the water use in the agricultural sectors of the WIOD has been calculated at the crop level (Genty et al., 2012), the MRIO only covers 35 sectors, with agricultural production grouped into one single industry, together with forestry and fishing. This can result in a sectoral aggregation bias when allocating the use of water of one country to the final demand of other. The problem lies on the implicit assumption of equal water intensities (per unit of output) across all grouped products. Similarly, the water content of one unit of output of the agriculture, fishing and forestry sector is also implicitly assumed to be the same irrespective of the industry buying their agricultural products (e.g. as if the food industry were merged with the paper industry), which is obviously not realistic. Su et al. (2010) offer a comprehensive review of the literature regarding this issue in relation to CO2 emissions; and by de Koning et al. (2015) and Schoer et al. (2013) does the same for raw materials. However, while this bias could affect the results for some specific small countries or products, it does not invalidate the aggregated results for most of the countries (e.g. Schoer et al., 2013).

On the other hand, the WIOD distinguishes 40 countries, covering more than $80 \%$ of global GDP, with the rest of the countries grouped in one single region, namely the RoW. Although the individual countries included in this region may not be so relevant from an economic point of view, the results of the whole region are important in terms of water, and this could lead to a bias due to the spatial aggregation of the Rest of the World (Su and Ang, 2010). However, this does not invalidate our results: the 40 countries explicitly included in our paper represent two thirds of the global use of water and $70 \%$ of the water footprint.

Another source of uncertainty is the quality of the data on the use of water in industry and services. While the data on the water use in the agriculture sector, hydropower production and households could be consider of high quality, the data on the water used by manufacturing industries and services are just rough estimates based on the water input coefficients of the EXIOBASE database and the water use reported by Mekonnen and Hoekstra (2011a) (see Genty et al., 2012). This data gap can, however, be considered a minor shortcoming, since the water use in those sectors is low compared to the other uses (e.g. according to Mekonnen and Hoekstra (2011a) the agricultural production contributes to more than $90 \%$ of the water use worldwide).

In spite of these limitations, the time series analyses provided in this paper are a good starting point to investigate changes in the use of water from a global perspective. Since water stress affects an ever higher number of regions, the availability of time series data for estimating the water used, consumed and traded between countries is an important starting point both for future researchers and for policies aimed at reducing water scarcity. 


\section{Conclusions}

In this paper, the World Input-Output Database (WIOD) and a multiregional input-output model have been used to estimate, for the first time, a time series data of water use, water footprint and virtual water trade balance. Data are presented disaggregated for 40 countries plus the rest of the world for the period 1995-2008.

The main results highlight that the majority of water use increases that took place between 1995 and 2008 mainly affected the water resources of developing countries. However, an increasing share of the water used in water-rich countries, such as China, Brazil, Canada, India and Indonesia (FAO, 2003) is devoted to sustain the consumption of developed countries. This fact is reflected in the growing quantity of water embodied in the exports from resource-rich developing countries to developed countries. These results link with previous studies analyzing global virtual water trade and comparative advantage (Debaere, 2014; Fracasso, 2014), and can also be used to expand this branch of the literature. In addition, increasing water consumption rates seem to be completely unsustainable in the medium-long term, with overall increases being $37 \%$ in the 14 years considered in this paper. Based on this annual growth rate, global water consumption would increase by a factor of 2 in the next 30 years.

The increasing water stress that exists at global level and the rising number of water-scarce countries, particularly located in developing areas of the globe, need to be urgently addressed by policies oriented to promote a sustainable and global management of water resources. The time series data provided in this paper offer essential information to support governments and international organizations in accounting not only for the domestic water supply, but also for the total water used worldwide to sustain the consumption of countries. Within this context, the quantification of water use, water footprint and the virtual water trade, together with the identification of the main water importer and exporter countries, are useful information to help assess each country's responsibilities in terms of water scarcities. The data provided in this paper can also be used to investigate the impacts of international trade, the water dependencies of countries and to provide scenario or forecasting exercises. By adopting a global perspective and by quantifying the water variation over time, this paper is a viable and good starting point for promoting analyses oriented towards the investigation of the main drivers and responsibilities related to water use, together with the planning of sustainable water policies.

\section{Disclaimer}

The views expressed are purely those of the authors and may not in any circumstances be regarded as stating an official position of the European Commission. 


\section{References}

Allan, J.A. (1993). Fortunately there are substitutes for water otherwise our hydro-political futures would be impossible. In: ODA, Editor (Ed.) Priorities for Water Resources Allocation and Management. Overseas Development Administration (ODA), London.

Antonelli, M., Roson, R., Sartori, M. (2012). Systemic input-output computation of green and blue virtual water 'flows' with an illustration for the Mediterranean region. Water Resoures Management 26 (14), 4133-4146.

Arto, I., Genty, A., Rueda-Cantuche, J.M., Villanueva, A., Andreoni, V. (2012a). Global Resources Use and Pollution. Vol. II, Country factsheets. Luxembourg. European Commission. ISBN 978-92-79-25941-8.

Arto, I., Genty, A., Rueda-Cantuche, J.M., Villanueva, A., Andreoni, V. (2012b). Global Resources Use and Pollution. Vol. I, Production, Consumption and Trade (1995-2008). Luxembourg. European Commission. ISBN 978-92-79-25929-6.

Carr, J.A., D’Orrico, P., Laio, F., Ridolfi, L. (2013) Recent history and geography of virtual water trade. PLoS ONE 8(2), 1-9.

Chapagain, A.K., Hoekstra, A.Y. (2007). The water footprint of coffee and tea consumption in the Netherlands. Ecological Economics 64(1), 109-118.

Chapagain, A.K., Hoekstra, A.Y. (2008). The global component of freshwater demand and supply: An assessment of virtual water flows between nations as a result of trade in agricultural and industrial products. Water International 33(1), 19-32.

Chapagain, A.K., Hoekstra, A.Y., Savenije, H.H.G., Gautam, R. (2006). The water footprint of cotton consumption: an assessment of the impact of worldwide consumption of cotton products on the water resources in the cotton producing countries. Ecological Economics 60(1), 186-203,.

Chapagain, A.K., Orr, S. (2009) An improved water footprint methodology linking global consumption to local water resources: A case of Spanish tomatoes. Journal of Environmental Management 90, 1219-1228.

de Koning, A., Bruckner, M., Lutter, S., Wood, R., Stadler, K., Tukker, A. (2015). Effect of aggregation and disaggregation on embodied material use of products in input-output analysis. Ecological Economics 116, 289-299.

Debaere, P. (2014). The global economics of water: Is water a source of comparative advantage. American Economic Journal: Applied Economics 6(2), 32-48.

EXIOPOL database: http://www.exiobase.eu/

FAO Statistics: http://www.fao.org/corp/statistics/en/

FAO (2003). Review of world water resources by country. Water reports, 23. Food and Agriculture Organization of yhe United Nations, Rome.

Feng, K., Hubacek, K., Minx, J., Siu, Y.L., Chapagain, A., Yu, Y., Guan, D., Barrett, J. (2011). Spatially explicit analysis of water footprints in the UK. Water 3(1), 47-63. 
Feng, K., Siu, Y.L., Guan, D. Hubacek, K. (2012). Assessing regional virtual water flows and water footprint in the Yellow River Basin, China: A consumption based approach. Applied Geography 32(2), 691-701.

Fracasso A. (2014). A gravity model of virtual water trade. Ecological Economics 108, 215-228

Genty, A., Arto, I., Neuwahl, F. (2012). Final database of environmental satellite accounts: technical report on their compilation. WIOD Documentation

Hoekstra A.Y. (2011). The global dimension of water governance: why the river basin approach is no longer sufficient and why cooperative action at global level is needed. Water 3, 21-46.

Hoekstra, A.Y., Chapagain, A.K. (2007). Globalization of water: Sharing the planet's freshwater resources. Blackwell, Oxford.

Hoekstra, A.Y., Chapagain, A.K., Aldaya, M.M., Mekonnen, M.M. (2011) The water footprint assessment manual: Setting the global standard, Earthscan, London, UK.

Hoekstra, A.Y., Hung, P.Q. (2002). Virtual water trade: A quantification of virtual water flows between nations in relation to international crop trade. UNESCO-IHE, Delft, The Netherlands. Value of Water Research Report Series No. 16.

Hoekstra, A.Y., Mekonnen, M.M. (2012). The water footprint of humanity. PNAS 109(9), 3232-3237.

Hoekstra, A.Y., Chapagain, A.K., Aldaya, M.M., Mekonnen, M.M. (2011) The water footprint assessment manual: Setting the global standard. Earthscan, London, UK.

Hubacek K., Guan D., Barrett J., Wiedmann T. (2009). Environmental implications of urbanization and lifestyle change in China: Ecological and Water Footprints. Journal of Cleaner Production 17(14), 1241-1248

Mekonnen, M., Hoekstra, A. (2010a) The green, blue and grey water footprint of farm animals and animal products, Value of Water Research Report Series No.48, Volume I and II. UNESCOIHE, Delft, the Netherlands.

Mekonnen, M., Hoekstra, A. (2010b). The green, blue and grey water footprint of crops and derived crop products. Value of Water Research Report Series No.47, Volume I and II. UNESCOIHE, Delft, the Netherlands.

Mekonnen, M., Hoekstra, A. (2011a). National water footprint accounts: the green, blue and grey water footprint of production and consumption. Value of Water Research Report Series No.50, Volume I and II. UNESCO-IHE, Delft, the Netherlands.

Mekonnen, M., Hoekstra, A. (2010b). The water footprint of electricity from hydropower. Value of Water Research Report Series No.51, UNESCO-IHE, Delft, the Netherlands.

Oki, T., Kanae, S. (2004). Virtual water trade and world water resources. Water Science and Technology 49(7), 203-209.

Rees, W.E. (1992). Ecological footprints and appropriated carrying capacity: what urban economics leaves out. Environment and Urbanization 4(2), 121-130.

Roson R., Sartori, M. (2015), A decomposition and comparison analysis of international water footprint time series. Sustainability 7, 5304-5320

Rosegrant, M., Cai, X., Cline, S. (2002). World Water and Food to 2025: Dealing with scarcity. Washington DC: International Food Policy Research Institute. 
Schoer, K., Wood, R., Arto, I., Weinzettel, J. (2013). Estimating Raw Material Equivalents on a Macro-Level: Comparison of Multi-Regional Input-Output Analysis and Hybrid LCI-IO. Environmental Science \& Technology 47 (24), 14282-14289.

Steen-Olsen, K., Weinzettel, J., Cranston, G., ErtugErcin, A., Hertwich, E.G. (2012). Carbon, Land, and Water Footprint Accounts for the European Union: Consumption, Production, and Displacements through International Trade. Environmental Science \& Technology 46(20), 10883-10891.

$\mathrm{Su}, \mathrm{B}$., Ang, B.W. (2010). Input-output analysis of $\mathrm{CO}_{2}$ emissions embodied in trade: the effects of spatial aggregation. Ecological Economics 70(1), 10-18.

Su, B., Huang, H.C., Ang, B.W., Zhou, P. (2010). Input-output analysis of $\mathrm{CO}_{2}$ emissions embodied in trade: the effects of sector aggregation. Energy Economics 32(1), 166-175.

Timmer, M., Erumban, A.A., Gouma, R., Los, B., Temurshoev, U., de Vries, G.J., Arto, I. (2012). The world input-output database (WIOD): contents, sources and methods.

Turner, K., Lenzen, K., Wiedmann, T., Barrett J. (2007) Examining the global environmental impact of regional consumption activities- Part 1: A Technical Note on Combining InputOutput and Ecological Footprint Analysis. Ecological Economics, 61(1), 6-10.

UNESCO WAPP. (2006) Water a shared responsibility. The United Nations, World Water Development Report 2, UN-WATER/WWAP/2006/3. Available at: http://unesdoc.unesco.org/images/0014/001444/144409e.pdf

Vorosmarty, C.J., Green, P., Salisbury, J., Lammers, R.B. (2000) Global water resources: vulnerability from climate change and population growth. Science 289, 284-288

Wiedmann, T. (2009). A review of recent multi-region input-output models used for consumptionbased emissions and resource accounting. Ecological Economics, 69, 211-222.

Wiedmann, T., Barrett, J. (2011). A greenhouse gas footprint analysis of UK Central Government, 1990-2008. Environmental Science \& Policy 14(8), 1041-1051

WIOD: http://www.wiod.org/

Wiedmann, T., Lenzen, M., Turner, K., Barrett, J. (2007) Examining the global environmental impact of regional consumption activities- Part 2: Review of input-output models for the assessment of environmental impacts embodied in trade. Ecological Economics 61(1), 15-26

Zhang, Z.; Yang, H.; Shi, M. (2011) Analyses of water footprint of Beijing in an interregional input-output framework. Ecological Economics 70, 2494-2502

Zimmer, D., Renault, D. (2003) Virtual water in food production and global trade: review of methodological issues and preliminary results. Proceedings of the expert meeting held 12-13 December 2002. Delft. The Netherlands. Editor Arjen Hoekstra. UNESCO-IHE. 


\section{Appendix}

Table A.1: Water use and percentage variation

$(1995-2008)\left(\mathrm{km}^{3}\right)$

\begin{tabular}{|c|c|c|c|c|c|c|c|c|c|c|c|}
\hline & 1995 & 2000 & 2001 & 2002 & 2003 & 2004 & 2005 & 2006 & 2007 & 2008 & 1995-2008 \\
\hline AUT & 15.6 & 16.5 & 16.5 & 16.2 & 14.2 & 16.1 & 15.6 & 15.0 & 15.4 & 16.6 & $6.80 \%$ \\
\hline BEL & 6.0 & 6.7 & 6.5 & 6.5 & 6.4 & 6.6 & 6.3 & 6.4 & 6.5 & 6.6 & $9.20 \%$ \\
\hline BGR & 25.6 & 18.6 & 20.8 & 21.8 & 18.4 & 25.4 & 22.8 & 23.3 & 17.9 & 26.7 & $4.30 \%$ \\
\hline CYP & 1.1 & 0.9 & 0.9 & 1.0 & 1.0 & 1.0 & 0.8 & 0.8 & 0.7 & 0.7 & $-38.00 \%$ \\
\hline CZE & 14.1 & 14.2 & 15.6 & 14.1 & 11.7 & 17.1 & 15.3 & 14.0 & 14.9 & 16.3 & $15.20 \%$ \\
\hline DNK & 9.7 & 9.9 & 9.7 & 9.2 & 9.6 & 9.8 & 9.8 & 9.4 & 9.4 & 10.1 & $4.10 \%$ \\
\hline EST & 2.7 & 3.5 & 3.0 & 2.9 & 2.8 & 3.2 & 4.1 & 3.4 & 4.7 & 4.4 & $60.80 \%$ \\
\hline FIN & 9.3 & 10.6 & 9.7 & 9.5 & 8.9 & 10.0 & 10.3 & 9.6 & 10.6 & 11.2 & $20.30 \%$ \\
\hline FRA & 96.9 & 108.2 & 104.1 & 108.7 & 95.8 & 110.4 & 103.6 & 101.7 & 100.9 & 110.5 & $14.00 \%$ \\
\hline DEU & 57.9 & 64.0 & 67.1 & 61.8 & 57.3 & 69.3 & 64.6 & 62.5 & 61.0 & 67.6 & $16.70 \%$ \\
\hline GRC & 19.2 & 19.9 & 19.2 & 18.9 & 17.2 & 18.7 & 19.5 & 18.4 & 16.9 & 17.5 & $-9.00 \%$ \\
\hline HUN & 26.9 & 24.0 & 30.3 & 26.1 & 23.0 & 34.8 & 32.2 & 30.6 & 25.4 & 35.3 & $31.10 \%$ \\
\hline IRL & 4.6 & 5.3 & 5.2 & 5.1 & 5.2 & 5.6 & 5.0 & 4.9 & 4.8 & 5.2 & $12.00 \%$ \\
\hline ITA & 79.0 & 81.4 & 79.2 & 79.2 & 72.8 & 86.3 & 81.2 & 77.7 & 75.6 & 80.6 & $2.00 \%$ \\
\hline LVA & 4.0 & 4.4 & 4.4 & 4.9 & 4.5 & 5.3 & 6.4 & 5.5 & 6.7 & 7.2 & $79.70 \%$ \\
\hline LTU & 7.4 & 9.5 & 8.4 & 9.4 & 9.9 & 10.4 & 10.5 & 7.4 & 11.2 & 12.3 & $65.80 \%$ \\
\hline LUX & 0.3 & 0.3 & 0.3 & 0.4 & 0.3 & 0.4 & 0.3 & 0.4 & 0.3 & 0.4 & $20.70 \%$ \\
\hline MLT & 0.1 & 0.1 & 0.1 & 0.1 & 0.1 & 0.1 & 0.1 & 0.1 & 0.1 & 0.1 & $-8.00 \%$ \\
\hline NLD & 6.0 & 6.1 & 5.7 & 5.7 & 5.5 & 5.8 & 5.6 & 5.5 & 5.5 & 5.9 & $-2.30 \%$ \\
\hline POL & 59.3 & 54.3 & 60.0 & 58.6 & 53.5 & 64.3 & 58.9 & 53.2 & 62.8 & 64.0 & $7.90 \%$ \\
\hline PRT & 17.5 & 17.7 & 16.2 & 16.5 & 16.4 & 16.8 & 11.8 & 17.0 & 14.3 & 15.5 & $-11.70 \%$ \\
\hline ROM & 53.1 & 37.3 & 51.7 & 43.8 & 43.6 & 64.4 & 56.6 & 52.1 & 35.3 & 54.5 & $2.70 \%$ \\
\hline SVK & 8.3 & 6.2 & 8.1 & 8.0 & 6.6 & 8.8 & 8.5 & 7.8 & 7.3 & 9.3 & $12.10 \%$ \\
\hline SVN & 2.8 & 3.0 & 3.0 & 3.1 & 2.6 & 3.3 & 3.1 & 3.0 & 3.2 & 3.3 & $19.00 \%$ \\
\hline ESP & 54.5 & 96.3 & 91.2 & 88.8 & 102.1 & 96.5 & 70.2 & 88.8 & 95.9 & 92.9 & $70.30 \%$ \\
\hline SWE & 25.7 & 29.1 & 28.9 & 26.0 & 22.6 & 24.7 & 27.2 & 23.2 & 25.4 & 26.4 & $2.60 \%$ \\
\hline GBR & 29.1 & 30.7 & 26.2 & 30.0 & 28.9 & 29.5 & 29.4 & 28.7 & 27.6 & 31.1 & $6.90 \%$ \\
\hline EU-27 & 637.0 & 678.5 & 691.8 & 676.1 & 641.0 & 744.7 & 679.8 & 670.4 & 660.4 & 732.0 & $14.90 \%$ \\
\hline AUS & 119.1 & 144.2 & 153.2 & 103.2 & 153.6 & 136.8 & 153.6 & 101.8 & 110.9 & 133.3 & $11.90 \%$ \\
\hline BRA & 479.4 & 523.1 & 553.3 & 578.8 & 639.6 & 656.6 & 649.8 & 674.1 & 712.7 & 762.2 & $59.00 \%$ \\
\hline CAN & 236.1 & 258.8 & 220.4 & 206.6 & 240.2 & 255.0 & 271.9 & 262.5 & 261.4 & 298.3 & $26.40 \%$ \\
\hline $\mathrm{CHN}$ & $1,108.5$ & $1,228.9$ & $1,251.6$ & $1,288.1$ & $1,281.1$ & $1,389.9$ & $1,446.5$ & $1,521.0$ & $1,589.7$ & $1,696.7$ & $53.10 \%$ \\
\hline IND & $1,136.7$ & $1,186.2$ & $1,205.5$ & $1,087.8$ & $1,254.8$ & $1,228.1$ & $1,292.2$ & $1,358.9$ & $1,493.7$ & $1,468.6$ & $29.20 \%$ \\
\hline IDN & 296.4 & 316.3 & 326.1 & 344.0 & 363.6 & 383.6 & 410.3 & 425.2 & 438.9 & 463.6 & $56.40 \%$ \\
\hline JPN & 64.9 & 64.3 & 63.2 & 62.4 & 63.6 & 64.3 & 60.9 & 62.5 & 59.8 & 60.5 & $-6.80 \%$ \\
\hline KOR & 20.3 & 20.7 & 21.0 & 19.8 & 19.3 & 20.6 & 20.4 & 20.4 & 20.2 & 21.2 & $4.70 \%$ \\
\hline MEX & 146.0 & 150.5 & 158.5 & 155.4 & 160.5 & 165.4 & 157.1 & 167.9 & 169.9 & 177.2 & $21.30 \%$ \\
\hline RUS & 415.8 & 413.4 & 480.6 & 487.4 & 429.1 & 478.4 & 487.3 & 497.7 & 509.5 & 606.2 & $45.80 \%$ \\
\hline TWN & 46.0 & 47.1 & 46.5 & 49.1 & 55.5 & 55.0 & 51.5 & 57.9 & 61.6 & 65.9 & $43.20 \%$ \\
\hline TUR & 114.1 & 126.7 & 115.2 & 125.7 & 121.5 & 132.7 & 136.3 & 137.3 & 120.1 & 121.3 & $6.30 \%$ \\
\hline USA & 1,017.1 & 1,118.9 & $1,075.9$ & $1,028.2$ & $1,106.8$ & $1,191.3$ & $1,170.3$ & $1,123.4$ & 1,179.1 & $1,193.5$ & $17.30 \%$ \\
\hline RoW & $2,903.2$ & $3,161.6$ & $3,334.1$ & $3,406.2$ & $3,526.5$ & $3,672.0$ & $3,867.1$ & $3,986.6$ & $4,057.0$ & 4,197.9 & $44.60 \%$ \\
\hline World & $8,740.6$ & $9,439.3$ & $9,696.9$ & $9,618.8$ & $10,056.6$ & $10,574.5$ & $10,855.1$ & $11,067.6$ & $11,444.9$ & $11,998.4$ & $37.30 \%$ \\
\hline
\end{tabular}

AUS: Australia, AUT: Austria, BEL: Belgium, BGR: Bulgaria, BRA: Brazil, CAN: Canada, CHN: China, CYP: Cyprus, CZE: Czech Republic, DEU: Germany, DNK: Denmark, ESP: Spain, EST: Estonia, FIN: Finland, FRA: France, GBR: United Kingdom, GRC: Greece, HUN: Hungary, IDN: Indonesia, IND: India, IRL: Ireland, ITA: Italy, JPN: Japan, KOR: South Korea, LTU: Lithuania, LUX: Luxembourg, LVA: Latvia, MEX: Mexico, MLT: Malta, NLD: Netherlands, POL: Poland, PRT: Portugal, ROM: Romania, ROW: Rest of the World, RUS: Russia, SVK: Slovak Republic, SVN: Slovenia, SWE: Sweden, TUR: Turkey, TWN: Taiwan, USA: United States. 
Table A.2: Per capita water use and percentage variation $(1995-2008)\left(\mathrm{m}^{3} / \mathrm{cap}\right)$

\begin{tabular}{|c|c|c|c|c|c|c|c|c|c|c|c|}
\hline & 1995 & 2000 & 2001 & 2002 & 2003 & 2004 & 2005 & 2006 & 2007 & 2008 & 1995-2008 \\
\hline AUT & 1,963 & 2,066 & 2,055 & 2,004 & 1,749 & 1,971 & 1,907 & 1,817 & 1,861 & 2,001 & $1.94 \%$ \\
\hline BEL & 593 & 656 & 631 & 634 & 619 & 635 & 604 & 604 & 613 & 615 & $3.67 \%$ \\
\hline BGR & 3,037 & 2,265 & 2,554 & 2,765 & 2,342 & 3,262 & 2,936 & 3,025 & 2,332 & 3,496 & $15.10 \%$ \\
\hline CYP & 1,780 & 1,282 & 1,313 & 1,465 & 1,440 & 1,364 & 1,089 & 1,038 & 956 & 902 & $-49.34 \%$ \\
\hline CZE & 1,368 & 1,377 & 1,516 & 1,383 & 1,146 & 1,674 & 1,492 & 1,367 & 1,449 & 1,568 & $14.64 \%$ \\
\hline DNK & 1,857 & 1,850 & 1,808 & 1,710 & 1,790 & 1,818 & 1,810 & 1,729 & 1,721 & 1,840 & $-0.88 \%$ \\
\hline EST & 1,892 & 2,558 & 2,160 & 2,149 & 2,087 & 2,398 & 3,014 & 2,529 & 3,493 & 3,286 & $73.67 \%$ \\
\hline FIN & 1,829 & 2,043 & 1,875 & 1,825 & 1,717 & 1,922 & 1,976 & 1,835 & 2,009 & 2,116 & $15.68 \%$ \\
\hline FRA & 1,634 & 1,788 & 1,707 & 1,769 & 1,549 & 1,772 & 1,651 & 1,608 & 1,585 & 1,726 & $5.62 \%$ \\
\hline DEU & 710 & 778 & 816 & 750 & 694 & 840 & 783 & 758 & 742 & 822 & $15.76 \%$ \\
\hline GRC & 1,814 & 1,823 & 1,759 & 1,727 & 1,566 & 1,694 & 1,755 & 1,650 & 1,515 & 1,559 & $-14.05 \%$ \\
\hline HUN & 2,604 & 2,348 & 2,970 & 2,561 & 2,272 & 3,439 & 3,190 & 3,035 & 2,527 & 3,513 & $34.94 \%$ \\
\hline IRL & 1,285 & 1,393 & 1,347 & 1,303 & 1,302 & 1,387 & 1,227 & 1,160 & 1,112 & 1,177 & $-8.44 \%$ \\
\hline ITA & 1,390 & 1,430 & 1,391 & 1,390 & 1,270 & 1,490 & 1,389 & 1,323 & 1,279 & 1,352 & $-2.75 \%$ \\
\hline LVA & 1,606 & 1,830 & 1,845 & 2,074 & 1,941 & 2,266 & 2,778 & 2,385 & 2,951 & 3,178 & $97.86 \%$ \\
\hline LTU & 2,031 & 2,703 & 2,411 & 2,705 & 2,847 & 3,031 & 3,072 & 2,186 & 3,311 & 3,644 & $79.44 \%$ \\
\hline LUX & 792 & 793 & 682 & 811 & 733 & 841 & 743 & 758 & 708 & 801 & $1.22 \%$ \\
\hline MLT & 255 & 224 & 213 & 214 & 209 & 218 & 212 & 223 & 210 & 211 & $-17.13 \%$ \\
\hline NLD & 391 & 386 & 359 & 352 & 339 & 359 & 345 & 335 & 337 & 359 & $-8.13 \%$ \\
\hline POL & 1,538 & 1,406 & 1,568 & 1,532 & 1,399 & 1,684 & 1,543 & 1,394 & 1,647 & 1,680 & $9.27 \%$ \\
\hline PRT & 1,748 & 1,735 & 1,582 & 1,593 & 1,574 & 1,599 & 1,124 & 1,609 & 1,348 & 1,457 & $-16.66 \%$ \\
\hline ROM & 2,336 & 1,661 & 2,307 & 2,008 & 2,003 & 2,966 & 2,615 & 2,413 & 1,635 & 2,530 & $8.31 \%$ \\
\hline SVK & 1,543 & 1,149 & 1,501 & 1,485 & 1,230 & 1,627 & 1,576 & 1,441 & 1,355 & 1,715 & $11.18 \%$ \\
\hline SVN & 1,412 & 1,505 & 1,486 & 1,553 & 1,316 & 1,651 & 1,553 & 1,522 & 1,572 & 1,663 & $17.78 \%$ \\
\hline ESP & 1,386 & 2,403 & 2,253 & 2,168 & 2,450 & 2,280 & 1,631 & 2,030 & 2,156 & 2,051 & $47.94 \%$ \\
\hline SWE & 2,916 & 3,288 & 3,251 & 2,916 & 2,523 & 2,756 & 3,017 & 2,564 & 2,788 & 2,872 & $-1.49 \%$ \\
\hline GBR & 503 & 521 & 444 & 507 & 486 & 494 & 489 & 476 & 454 & 509 & $1.19 \%$ \\
\hline EU-27 & 1,331 & 1,405 & 1,430 & 1,395 & 1,317 & 1,523 & 1,384 & 1,359 & 1,333 & 1,471 & $10.50 \%$ \\
\hline AUS & 6,572 & 7,524 & 7,904 & 5,265 & 7,741 & 6,806 & 7,526 & 4,907 & 5,253 & 6,195 & $-5.74 \%$ \\
\hline BRA & 2,962 & 2,999 & 3,128 & 3,228 & 3,521 & 3,571 & 3,494 & 3,586 & 3,755 & 3,979 & $34.34 \%$ \\
\hline CAN & 8,057 & 8,438 & 7,119 & 6,604 & 7,601 & 7,984 & 8,423 & 8,045 & 7,925 & 8,952 & $11.11 \%$ \\
\hline CHN & 913 & 968 & 979 & 1,002 & 990 & 1,069 & 1,106 & 1,157 & 1,203 & 1,277 & $39.90 \%$ \\
\hline IND & 1,179 & 1,126 & 1,125 & 999 & 1,135 & 1,094 & 1,134 & 1,174 & 1,272 & 1,233 & $4.64 \%$ \\
\hline IDN & 1,487 & 1,482 & 1,508 & 1,571 & 1,639 & 1,708 & 1,805 & 1,849 & 1,888 & 1,973 & $32.73 \%$ \\
\hline JPN & 522 & 512 & 502 & 495 & 504 & 509 & 482 & 495 & 473 & 478 & $-8.32 \%$ \\
\hline KOR & 454 & 451 & 455 & 427 & 413 & 439 & 435 & 431 & 426 & 445 & $-2.07 \%$ \\
\hline MEX & 1,583 & 1,506 & 1,565 & 1,514 & 1,545 & 1,573 & 1,475 & 1,557 & 1,555 & 1,601 & $1.18 \%$ \\
\hline RUS & 2,796 & 2,817 & 3,288 & 3,349 & 2,962 & 3,315 & 3,388 & 3,468 & 3,556 & 4,234 & $51.45 \%$ \\
\hline TWN & 2,175 & 2,147 & 2,103 & 2,207 & 2,473 & 2,436 & 2,268 & 2,533 & 2,680 & 2,856 & $31.28 \%$ \\
\hline TUR & 1,938 & 1,991 & 1,784 & 1,920 & 1,831 & 1,974 & 2,000 & 1,988 & 1,715 & 1,711 & $-11.75 \%$ \\
\hline USA & 3,819 & 3,961 & 3,768 & 3,564 & 3,800 & 4,051 & 3,943 & 3,750 & 3,901 & 3,913 & $2.47 \%$ \\
\hline RoW & 1,525 & 1,511 & 1,564 & 1,569 & 1,595 & 1,632 & 1,688 & 1,710 & 1,710 & 1,739 & $14.03 \%$ \\
\hline World & 1,526 & 1,542 & 1,564 & 1,532 & 1,583 & 1,645 & 1,668 & 1,681 & 1,718 & 1,780 & $16.63 \%$ \\
\hline
\end{tabular}

AUS: Australia, AUT: Austria, BEL: Belgium, BGR: Bulgaria, BRA: Brazil, CAN: Canada, CHN: China, CYP: Cyprus, CZE: Czech Republic, DEU: Germany, DNK: Denmark, ESP: Spain, EST: Estonia, FIN: Finland, FRA: France, GBR: United Kingdom, GRC: Greece, HUN: Hungary, IDN: Indonesia, IND: India, IRL: Ireland, ITA: Italy, JPN: Japan, KOR: South Korea, LTU: Lithuania, LUX: Luxembourg, LVA: Latvia, MEX: Mexico, MLT: Malta, NLD: Netherlands, POL: Poland, PRT: Portugal, ROM: Romania, ROW: Rest of the world, RUS: Russia, SVK: Slovak Republic, SVN: Slovenia, SWE: Sweden, TUR: Turkey, TWN: Taiwan, USA: United States. 
Table A.3: Water footprint and percentage variation $(1995-2008)\left(\mathrm{km}^{3}\right)$

\begin{tabular}{|c|c|c|c|c|c|c|c|c|c|c|c|}
\hline & 1995 & 2000 & 2001 & 2002 & 2003 & 2004 & 2005 & 2006 & 2007 & 2008 & $1995-2008$ \\
\hline AUT & 24.0 & 23.7 & 24.4 & 22.4 & 22.0 & 25.3 & 25.0 & 24.8 & 25.2 & 27.2 & $13.20 \%$ \\
\hline BEL & 20.4 & 23.9 & 24.8 & 25.6 & 29.9 & 31.7 & 33.0 & 33.7 & 34.1 & 35.3 & $72.90 \%$ \\
\hline BGR & 20.3 & 14.4 & 16.8 & 16.0 & 13.8 & 18.9 & 17.6 & 17.3 & 14.2 & 18.5 & $-8.70 \%$ \\
\hline CYP & 1.6 & 1.7 & 1.8 & 1.8 & 1.9 & 1.9 & 1.9 & 1.9 & 2.0 & 2.5 & $53.70 \%$ \\
\hline CZE & 14.7 & 15.0 & 17.2 & 16.6 & 15.0 & 19.8 & 17.9 & 17.5 & 18.2 & 20.4 & $38.50 \%$ \\
\hline DNK & 13.6 & 12.6 & 12.9 & 13.0 & 14.1 & 15.1 & 15.5 & 15.2 & 16.4 & 17.2 & $26.90 \%$ \\
\hline EST & 1.6 & 2.8 & 2.8 & 2.9 & 3.2 & 2.4 & 2.5 & 3.3 & 4.2 & 3.8 & $136.50 \%$ \\
\hline FIN & 11.8 & 13.0 & 13.2 & 13.2 & 13.6 & 15.1 & 16.5 & 16.2 & 17.2 & 19.3 & $64.40 \%$ \\
\hline FRA & 129.6 & 137.7 & 141.9 & 144.6 & 143.1 & 157.6 & 152.5 & 151.0 & 155.6 & 165.0 & $27.30 \%$ \\
\hline DEU & 168.7 & 171.7 & 172.2 & 161.9 & 175.8 & 190.4 & 180.9 & 185.5 & 194.3 & 202.3 & $19.90 \%$ \\
\hline GRC & 24.3 & 26.6 & 26.6 & 28.0 & 27.0 & 30.0 & 29.6 & 29.5 & 30.0 & 32.2 & $32.50 \%$ \\
\hline HUN & 21.1 & 21.0 & 26.0 & 23.4 & 21.4 & 30.1 & 27.4 & 25.3 & 20.7 & 26.5 & $25.60 \%$ \\
\hline IRL & 4.4 & 6.6 & 7.1 & 7.8 & 7.7 & 8.0 & 8.1 & 9.1 & 10.3 & 11.4 & $158.20 \%$ \\
\hline ITA & 122.2 & 127.8 & 129.7 & 130.0 & 132.0 & 150.6 & 144.4 & 144.3 & 142.7 & 149.8 & $22.60 \%$ \\
\hline LVA & 3.6 & 4.3 & 4.5 & 5.0 & 4.7 & 5.6 & 6.3 & 6.0 & 7.4 & 7.5 & $111.60 \%$ \\
\hline LTU & 5.5 & 8.4 & 7.4 & 8.4 & 8.7 & 10.2 & 10.1 & 7.8 & 9.7 & 10.4 & $91.30 \%$ \\
\hline LUX & 1.3 & 1.3 & 1.2 & 1.3 & 1.3 & 1.6 & 1.6 & 1.6 & 1.6 & 1.8 & $46.10 \%$ \\
\hline MLT & 0.5 & 0.6 & 0.6 & 0.6 & 0.6 & 0.6 & 0.6 & 0.6 & 0.8 & 0.8 & $48.80 \%$ \\
\hline NLD & 35.0 & 36.2 & 41.2 & 42.1 & 43.0 & 43.7 & 43.1 & 43.8 & 45.9 & 51.6 & $47.50 \%$ \\
\hline POL & 56.0 & 56.7 & 61.9 & 59.4 & 53.0 & 63.1 & 58.8 & 55.5 & 64.3 & 69.2 & $23.40 \%$ \\
\hline PRT & 24.9 & 25.9 & 26.0 & 25.8 & 26.1 & 27.4 & 22.1 & 26.2 & 25.9 & 27.7 & $11.30 \%$ \\
\hline ROM & 50.0 & 35.2 & 49.7 & 41.7 & 43.0 & 62.8 & 55.8 & 52.9 & 39.5 & 56.8 & $13.60 \%$ \\
\hline SVK & 8.1 & 6.9 & 8.7 & 8.4 & 7.7 & 10.5 & 10.4 & 10.1 & 10.8 & 12.8 & $59.50 \%$ \\
\hline SVN & 4.3 & 4.2 & 4.2 & 4.4 & 4.3 & 4.9 & 4.7 & 4.6 & 5.1 & 6.0 & $39.30 \%$ \\
\hline ESP & 80.5 & 110.7 & 111.6 & 111.0 & 126.6 & 129.9 & 113.5 & 128.4 & 140.1 & 139.4 & $73.10 \%$ \\
\hline SWE & 30.2 & 34.6 & 33.4 & 32.1 & 30.4 & 32.6 & 34.2 & 32.0 & 35.3 & 36.6 & $21.20 \%$ \\
\hline GBR & 85.0 & 105.2 & 105.5 & 109.6 & 112.9 & 135.3 & 138.5 & 142.2 & 143.7 & 142.5 & $67.70 \%$ \\
\hline EU-27 & 963.1 & $1,028.6$ & $1,073.3$ & $1,056.8$ & $1,083.0$ & $1,225.2$ & $1,172.5$ & $1,186.1$ & $1,215.3$ & $1,294.8$ & $34.40 \%$ \\
\hline AUS & 83.8 & 98.9 & 104.0 & 74.8 & 122.7 & 115.1 & 133.6 & 97.4 & 112.6 & 122.1 & $45.60 \%$ \\
\hline BRA & 434.5 & 456.3 & 444.6 & 445.5 & 493.3 & 484.6 & 498.4 & 526.5 & 563.3 & 610.3 & $40.50 \%$ \\
\hline CAN & 175.9 & 191.0 & 172.0 & 170.6 & 202.3 & 211.3 & 225.8 & 225.6 & 229.6 & 248.6 & $41.40 \%$ \\
\hline CHN & $1,003.9$ & $1,157.3$ & $1,188.8$ & $1,211.0$ & 1,191.1 & $1,288.4$ & $1,293.8$ & $1,326.4$ & $1,385.9$ & $1,468.3$ & $46.30 \%$ \\
\hline IND & $1,063.5$ & $1,090.3$ & $1,118.3$ & $1,005.0$ & $1,169.9$ & 1,139.2 & $1,208.8$ & $1,261.8$ & $1,390.5$ & $1,362.7$ & $28.10 \%$ \\
\hline IDN & 275.9 & 285.9 & 296.7 & 317.3 & 337.4 & 350.7 & 371.0 & 389.5 & 403.4 & 419.6 & $52.10 \%$ \\
\hline JPN & 294.8 & 259.8 & 250.0 & 234.1 & 243.0 & 259.0 & 256.9 & 248.2 & 234.3 & 258.9 & $-12.20 \%$ \\
\hline KOR & 63.0 & 57.3 & 61.1 & 62.4 & 64.3 & 70.9 & 70.0 & 74.2 & 75.6 & 82.8 & $31.50 \%$ \\
\hline MEX & 142.8 & 169.9 & 181.4 & 178.9 & 184.2 & 190.9 & 184.5 & 197.1 & 202.7 & 215.2 & $50.70 \%$ \\
\hline RUS & 406.6 & 372.2 & 448.5 & 455.9 & 416.2 & 475.6 & 501.3 & 506.4 & 548.2 & 659.4 & $62.20 \%$ \\
\hline TWN & 61.8 & 64.4 & 63.5 & 61.9 & 66.8 & 69.4 & 67.8 & 73.0 & 73.4 & 77.5 & $25.40 \%$ \\
\hline TUR & 112.8 & 131.0 & 109.6 & 124.3 & 126.6 & 139.3 & 143.6 & 145.5 & 136.7 & 142.3 & $26.20 \%$ \\
\hline USA & $1,083.8$ & 1,318.0 & $1,291.2$ & $1,239.4$ & $1,328.8$ & $1,428.9$ & $1,444.3$ & $1,404.5$ & 1,397.1 & 1,363.9 & $25.80 \%$ \\
\hline RoW & $2,574.3$ & $2,758.4$ & $2,894.0$ & 2,980.7 & $3,026.7$ & $3,126.0$ & $3,282.7$ & $3,405.3$ & $3,476.3$ & $3,672.2$ & $42.60 \%$ \\
\hline World & $8,740.6$ & $9,439.3$ & $9,696.9$ & $9,618.8$ & $10,056.6$ & $10,574.5$ & $10,855.1$ & $11,067.6$ & $11,444.9$ & $11,998.4$ & $37.30 \%$ \\
\hline
\end{tabular}

AUS: Australia, AUT: Austria, BEL: Belgium, BGR: Bulgaria, BRA: Brazil, CAN: Canada, CHN: China, CYP: Cyprus, CZE: Czech Republic, DEU: Germany, DNK: Denmark, ESP: Spain, EST: Estonia, FIN: Finland, FRA: France, GBR: United Kingdom, GRC: Greece, HUN: Hungary, IDN: Indonesia, IND: India, IRL: Ireland, ITA: Italy, JPN: Japan, KOR: South Korea, LTU: Lithuania, LUX: Luxembourg, LVA: Latvia, MEX: Mexico, MLT: Malta, NLD: Netherlands, POL: Poland, PRT: Portugal, ROM: Romania, ROW: Rest of the World, RUS: Russia, SVK: Slovak Republic, SVN: Slovenia, SWE: Sweden, TUR: Turkey, TWN: Taiwan, USA: United States. 
Table A.4: Per capita water footprint and percentage variation (1995-2008) ( $\mathrm{m}^{3} /$ inhabitant)

\begin{tabular}{|c|c|c|c|c|c|c|c|c|c|c|c|}
\hline & 1995 & 2000 & 2001 & 2002 & 2003 & 2004 & 2005 & 2006 & 2007 & 2008 & $1995-2008$ \\
\hline AUT & 3,019 & 2,962 & 3,037 & 2,784 & 2,710 & 3,113 & 3,050 & 3,003 & 3,046 & 3,265 & $8.12 \%$ \\
\hline BEL & 2,018 & 2,334 & 2,415 & 2,479 & 2,884 & 3,048 & 3,157 & 3,203 & 3,219 & 3,313 & $64.17 \%$ \\
\hline BRA & 2,685 & 2,616 & 2,513 & 2,485 & 2,716 & 2,635 & 2,680 & 2,801 & 2,968 & 3,186 & $18.68 \%$ \\
\hline BGR & 2,404 & 1,757 & 2,059 & 2,033 & 1,757 & 2,422 & 2,262 & 2,239 & 1,849 & 2,422 & $0.74 \%$ \\
\hline CYP & 2,471 & 2,418 & 2,644 & 2,554 & 2,688 & 2,611 & 2,596 & 2,460 & 2,531 & 3,105 & $25.66 \%$ \\
\hline CZE & 1,426 & 1,458 & 1,671 & 1,626 & 1,469 & 1,941 & 1,753 & 1,708 & 1,765 & 1,966 & $37.83 \%$ \\
\hline DNK & 2,604 & 2,365 & 2,416 & 2,412 & 2,611 & 2,801 & 2,871 & 2,807 & 3,017 & 3,146 & $20.85 \%$ \\
\hline EST & 1,120 & 2,065 & 2,068 & 2,105 & 2,352 & 1,804 & 1,840 & 2,441 & 3,161 & 2,861 & $155.37 \%$ \\
\hline FIN & 2,307 & 2,507 & 2,555 & 2,533 & 2,616 & 2,900 & 3,155 & 3,080 & 3,262 & 3,647 & $58.10 \%$ \\
\hline FRA & 2,186 & 2,274 & 2,327 & 2,354 & 2,314 & 2,531 & 2,430 & 2,388 & 2,444 & 2,579 & $17.98 \%$ \\
\hline DEU & 2,069 & 2,090 & 2,094 & 1,964 & 2,130 & 2,307 & 2,192 & 2,250 & 2,361 & 2,461 & $18.93 \%$ \\
\hline GRC & 2,294 & 2,440 & 2,431 & 2,554 & 2,458 & 2,714 & 2,666 & 2,652 & 2,686 & 2,871 & $25.18 \%$ \\
\hline HUN & 2,042 & 2,050 & 2,550 & 2,301 & 2,113 & 2,977 & 2,711 & 2,511 & 2,054 & 2,639 & $29.28 \%$ \\
\hline IRL & 1,228 & 1,759 & 1,853 & 2,000 & 1,945 & 1,981 & 1,963 & 2,157 & 2,387 & 2,590 & $111.02 \%$ \\
\hline ITA & 2,150 & 2,245 & 2,276 & 2,281 & 2,304 & 2,601 & 2,469 & 2,455 & 2,414 & 2,512 & $16.87 \%$ \\
\hline LVA & 1,426 & 1,791 & 1,882 & 2,122 & 2,023 & 2,422 & 2,751 & 2,596 & 3,229 & 3,322 & $132.95 \%$ \\
\hline LTU & 1,499 & 2,390 & 2,132 & 2,411 & & & & 93 & & 03 & $106.97 \%$ \\
\hline LUX & 3,090 & 2,958 & 2,780 & 2,893 & 3,004 & 3,437 & 3,472 & 3,438 & 3,460 & 3,785 & $22.49 \%$ \\
\hline MLT & 1,473 & 1,518 & 1,591 & 1,568 & 1,606 & 1,383 & 1,485 & 1,578 & 1,843 & 1,973 & $34.01 \%$ \\
\hline NLD & 2,267 & 2,279 & 2,579 & 2,612 & 2,654 & 2,686 & 2,646 & 2,680 & 2,809 & 3,143 & $38.65 \%$ \\
\hline POL & 1,452 & 1,467 & 1,617 & 1,554 & 1,386 & 1,653 & 1,540 & 1,453 & 1,686 & 1,814 & $24.95 \%$ \\
\hline PRT & 2,486 & 2,542 & 2,538 & 2,495 & 2,513 & 2,619 & 2,096 & 2,477 & 2,443 & 2,610 & $5.01 \%$ \\
\hline ROM & 2,202 & 1,568 & 2,214 & 1,911 & 1,977 & 2,893 & 2,575 & 2,448 & 1,831 & 2,640 & $19.89 \%$ \\
\hline SVK & 1,503 & 1,280 & 1,617 & 1,563 & & & & & & 78 & \\
\hline SVN & 2,158 & 2,130 & 2,119 & 2,184 & 2,155 & 2,463 & 2,350 & 2,310 & 2,523 & 2,976 & $37.88 \%$ \\
\hline ESP & 2,046 & 2,765 & 2,757 & 2,711 & 3,038 & 3,067 & 2,637 & 2,933 & 3,151 & 3,078 & $50.43 \%$ \\
\hline SWE & 3,425 & 3,904 & 3,763 & 3,599 & 3,402 & 3,635 & 3,797 & 3,540 & 3,868 & 3,985 & $16.36 \%$ \\
\hline GBR & 1,467 & 1,789 & 1,788 & 1,850 & 1,899 & 2,266 & 2,308 & 2,354 & 2,365 & 2,329 & $58.78 \%$ \\
\hline EU-27 & 2,012 & 2,131 & 2,219 & 2,181 & 2,225 & 2,507 & 2,387 & 2,405 & 2,454 & 2,602 & $29.27 \%$ \\
\hline AUS & 4,627 & 5,159 & 5,365 & 3,814 & 6,186 & 5,724 & 6,546 & 4,696 & 5,333 & 5,673 & $22.62 \%$ \\
\hline BRA & 2,685 & 2,616 & 2,513 & 2,485 & 2,716 & 2,635 & 2,680 & 2,801 & 2,968 & 3,186 & $0.65 \%$ \\
\hline CAN & 6,002 & 6,229 & 5,553 & 5,453 & 6,402 & 6,613 & 6,995 & 6,915 & 6,962 & 7,459 & $24.29 \%$ \\
\hline CHN & 827 & 912 & 930 & 942 & 921 & 991 & 989 & 1,009 & 1,049 & 1,105 & $33.67 \%$ \\
\hline IND & 1,103 & 1,035 & 1,044 & 923 & 1,058 & 1,014 & 1,060 & 1,091 & 1,184 & 1,144 & $3.78 \%$ \\
\hline IDN & 1,384 & 1,340 & 1,372 & 1,449 & 1,521 & 1,562 & 1,632 & 1,694 & 1,735 & 1,786 & $29.05 \%$ \\
\hline JPN & 2,368 & 2,066 & 1,986 & 1,857 & 1,926 & 2,051 & 2,033 & 1,962 & 1,852 & 2,046 & $-13.62 \%$ \\
\hline KOR & 1,410 & 1,246 & 1,322 & 1,345 & 1,380 & 1,514 & 1,487 & 1,570 & 1,591 & 1,734 & $23.00 \%$ \\
\hline MEX & 1,548 & 1,700 & 1,790 & 1,743 & 1,773 & 1,815 & 1,733 & 1,827 & 1,856 & 1,946 & $25.69 \%$ \\
\hline RUS & 2,734 & 2,536 & 3,069 & 3,133 & 2,873 & 3,296 & 3,485 & 3,528 & 3,826 & 4,606 & $68.45 \%$ \\
\hline TWN & 2,920 & 2,938 & 2,872 & 2,782 & 2,979 & 3,075 & 2,985 & 3,193 & 3,197 & 3,357 & $14.96 \%$ \\
\hline TUR & 1,916 & 2,058 & 1,699 & 1,899 & 1,909 & 2,072 & 2,107 & 2,107 & 1,953 & 2,006 & $4.72 \%$ \\
\hline USA & 4,069 & 4,666 & 4,522 & 4,297 & 4,562 & 4,859 & 4,866 & 4,689 & 4,622 & 4,472 & $9.89 \%$ \\
\hline RoW & 1,352 & 1,318 & 1,358 & 1,373 & 1,369 & 1,389 & 1,433 & 1,461 & 1,465 & 1,521 & $12.49 \%$ \\
\hline WORLD & 1,526 & 1,542 & 1,564 & 1,532 & 1,583 & 1,645 & 1,668 & 1,681 & 1,718 & 1,780 & $16.63 \%$ \\
\hline
\end{tabular}

AUS: Australia, AUT: Austria, BEL: Belgium, BGR: Bulgaria, BRA: Brazil, CAN: Canada, CHN: China, CYP: Cyprus, CZE: Czech Republic, DEU: Germany, DNK: Denmark, ESP: Spain, EST: Estonia, FIN: Finland, FRA: France, GBR: United Kingdom, GRC: Greece, HUN: Hungary, IDN: Indonesia, IND: India, IRL: Ireland, ITA: Italy, JPN: Japan, KOR: South Korea, LTU: Lithuania, LUX: Luxembourg, LVA: Latvia, MEX: Mexico, MLT: Malta, NLD: Netherlands, POL: Poland, PRT: Portugal, ROM: Romania, ROW: Rest of the World, RUS: Russia, SVK: Slovak Republic, SVN: Slovenia, SWE: Sweden, TUR: Turkey, TWN: Taiwan, USA: United States. 
Table A.5: Domestic coverage ratio (\%)

\begin{tabular}{lrrrr}
\hline & $\mathbf{1 9 9 5}$ & $\mathbf{2 0 0 0}$ & $\mathbf{2 0 0 5}$ & $\mathbf{2 0 0 8}$ \\
\hline AUS & 142.0 & 145.9 & 115.0 & 109.2 \\
BRA & 110.3 & 114.7 & 130.4 & 124.9 \\
\hline CAN & 134.2 & 135.5 & 120.4 & 120.0 \\
CHN & 110.4 & 106.2 & 111.8 & 115.6 \\
\hline EU-27 & 66.1 & 66.0 & 58.0 & 56.5 \\
IND & 106.9 & 108.8 & 106.9 & 107.8 \\
\hline IDN & 107.4 & 110.6 & 110.6 & 110.5 \\
JPN & 22.0 & 24.8 & 23.7 & 23.4 \\
KOR & 32.2 & 36.2 & 29.2 & 25.6 \\
MEX & 102.2 & 88.6 & 85.1 & 82.3 \\
RUS & 102.3 & 111.1 & 97.2 & 91.9 \\
TWN & 74.5 & 73.1 & 76.0 & 85.1 \\
\hline TUR & 101.2 & 96.7 & 94.9 & 85.3 \\
USA & 93.8 & 84.9 & 81.0 & 87.5 \\
RoW & 112.8 & 114.6 & 117.8 & 114.3 \\
Total & 100.0 & 100.0 & 100.0 & 100.0
\end{tabular}

AUS: Australia; BRA: Brazil; CAN: Canada; CHN: China; EU-27: European Union; IDN: Indonesia; IND: India; JPN: Japan; KOR: South Korea; MEX: Mexico; RoW: Rest of the World; RUS: Russia; TWN: Taiwan; TUR: Turkey; USA: United States. 
Table A.6: Imports, exports and percentage variations

(1995-2008) $\left(\mathrm{km}^{3}\right)$

\begin{tabular}{|c|c|c|c|c|c|c|c|c|c|c|}
\hline $\mathrm{km}^{3}$ & 1995 & 1995 & 2000 & 2000 & 2005 & 2005 & 2008 & 2008 & 2008-1995 & 2008-1995 \\
\hline & Import & Export & Import & Export & Import & Export & Import & Export & Import Variation & Export Variation \\
\hline AUT & 11.8 & 3.4 & 11.8 & 4.6 & 14.9 & 5.5 & 17.0 & 6.5 & $44.5 \%$ & $91.9 \%$ \\
\hline BEL & 18.2 & 3.8 & 21.8 & 4.6 & 31.3 & 4.6 & 33.7 & 4.9 & $84.8 \%$ & $29.2 \%$ \\
\hline BGR & 1.5 & 6.8 & 1.3 & 5.4 & 2.0 & 7.3 & 4.4 & 12.6 & $200.1 \%$ & $85.4 \%$ \\
\hline CYP & 0.9 & 0.5 & 1.1 & 0.3 & 1.4 & 0.3 & 2.1 & 0.3 & $118.5 \%$ & $-35.7 \%$ \\
\hline CZE & 5.1 & 4.5 & 5.4 & 4.6 & 8.7 & 6.1 & 11.0 & 6.9 & $115.1 \%$ & $52.7 \%$ \\
\hline DNK & 9.8 & 5.9 & 9.0 & 6.2 & 11.6 & 5.8 & 13.5 & 6.3 & $37.4 \%$ & $7.0 \%$ \\
\hline EST & 0.5 & 1.6 & 1.1 & 1.8 & 1.7 & 3.2 & 2.0 & 2.6 & $310.4 \%$ & $59.7 \%$ \\
\hline FIN & 5.7 & 3.3 & 6.6 & 4.2 & 9.7 & 3.6 & 11.9 & 3.8 & $108.5 \%$ & $16.1 \%$ \\
\hline FRA & 59.3 & 26.6 & 62.3 & 32.8 & 79.9 & 31.0 & 90.8 & 36.2 & $53.1 \%$ & $36.1 \%$ \\
\hline DEU & 122.5 & 11.7 & 124.9 & 17.1 & 137.5 & 21.2 & 160.1 & 25.4 & $30.7 \%$ & $117.0 \%$ \\
\hline GRC & 7.5 & 2.5 & 9.4 & 2.7 & 12.5 & 2.4 & 16.8 & 2.0 & $122.2 \%$ & $-16.9 \%$ \\
\hline HUN & 3.0 & 8.8 & 4.0 & 7.1 & 5.3 & 10.2 & 6.6 & 15.4 & $119.4 \%$ & $74.4 \%$ \\
\hline IRL & 2.7 & 2.9 & 4.3 & 2.9 & 6.1 & 3.1 & 9.2 & 2.9 & $235.3 \%$ & $0.2 \%$ \\
\hline ITA & 58.7 & 15.5 & 62.6 & 16.3 & 79.9 & 16.7 & 87.8 & 18.6 & $49.5 \%$ & $19.5 \%$ \\
\hline LVA & 0.6 & 1.0 & 1.1 & 1.2 & 1.7 & 1.8 & 2.6 & 2.3 & $352.1 \%$ & $121.8 \%$ \\
\hline LTU & 1.1 & 3.0 & 1.7 & 2.8 & 2.4 & 2.9 & 3.8 & 5.6 & $255.5 \%$ & $87.4 \%$ \\
\hline LUX & 1.1 & 0.2 & 1.2 & 0.3 & 1.5 & 0.2 & 1.7 & 0.3 & $53.4 \%$ & $46.2 \%$ \\
\hline MLT & 0.5 & 0.0 & 0.5 & 0.0 & 0.5 & 0.0 & 0.7 & 0.0 & $63.0 \%$ & $201.6 \%$ \\
\hline NLD & 33.9 & 4.9 & 35.0 & 4.9 & 42.1 & 4.6 & 50.6 & 5.0 & $49.6 \%$ & $1.1 \%$ \\
\hline POL & 7.3 & 10.6 & 11.2 & 8.8 & 15.4 & 15.5 & 24.4 & 19.3 & $235.1 \%$ & $82.2 \%$ \\
\hline PRT & 10.2 & 2.8 & 11.7 & 3.4 & 12.8 & 2.6 & 16.2 & 3.9 & $58.3 \%$ & $39.0 \%$ \\
\hline ROM & 2.6 & 5.6 & 3.2 & 5.3 & 6.6 & 7.5 & 11.0 & 8.6 & $327.1 \%$ & $53.3 \%$ \\
\hline SVK & 2.1 & 2.4 & 2.4 & 1.6 & 4.7 & 2.8 & 6.7 & 3.1 & $211.4 \%$ & $31.9 \%$ \\
\hline SVN & 2.2 & 0.7 & 2.1 & 0.9 & 2.6 & 1.0 & 4.0 & 1.3 & $81.5 \%$ & $89.5 \%$ \\
\hline ESP & 37.8 & 11.8 & 42.0 & 27.5 & 64.7 & 21.3 & 76.8 & 30.3 & $103.1 \%$ & $155.6 \%$ \\
\hline SWE & 10.3 & 5.8 & 12.2 & 6.7 & 14.7 & 7.7 & 17.9 & 7.7 & $73.7 \%$ & $32.2 \%$ \\
\hline GBR & 62.0 & 6.1 & 79.8 & 5.3 & 114.5 & 5.3 & 117.0 & 5.7 & $88.9 \%$ & $-7.4 \%$ \\
\hline sum EU-276 & 479.0 & 152.9 & 529.5 & 179.4 & 687.0 & 194.3 & 800.4 & 237.7 & $67.1 \%$ & $55.4 \%$ \\
\hline EU-27 ${ }^{7}$ & 380.3 & 54.3 & 412.9 & 62.8 & 562.1 & 69.4 & 655.0 & 92.3 & $72.2 \%$ & $70.1 \%$ \\
\hline AUS & 16.2 & 51.4 & 19.8 & 65.2 & 29.1 & 49.1 & 33.5 & 44.8 & $107.6 \%$ & $-12.9 \%$ \\
\hline BRA & 24.6 & 69.5 & 22.9 & 89.8 & 19.3 & 170.7 & 35.8 & 187.7 & $45.3 \%$ & $170.0 \%$ \\
\hline CAN & 35.3 & 95.5 & 45.9 & 113.7 & 61.3 & 107.4 & 73.7 & 123.4 & $109.0 \%$ & $29.3 \%$ \\
\hline CHN & 43.6 & 148.2 & 65.7 & 137.3 & 131.2 & 283.9 & 241.0 & 469.4 & $452.6 \%$ & $216.8 \%$ \\
\hline IND & 13.4 & 86.6 & 19.3 & 115.3 & 41.3 & 124.7 & 49.9 & 155.8 & $272.3 \%$ & $79.9 \%$ \\
\hline IDN & 14.5 & 35.0 & 18.7 & 49.1 & 22.8 & 62.1 & 30.4 & 74.4 & $109.7 \%$ & $112.6 \%$ \\
\hline JPN & 233.2 & 3.3 & 199.3 & 3.9 & 200.8 & 4.7 & 204.1 & 5.7 & $-12.5 \%$ & $73.2 \%$ \\
\hline KOR & 44.9 & 2.2 & 38.9 & 2.3 & 51.8 & 2.3 & 64.2 & 2.7 & $43.2 \%$ & $23.1 \%$ \\
\hline MEX & 18.1 & 21.3 & 37.8 & 18.5 & 47.8 & 20.4 & 61.1 & 23.0 & $238.2 \%$ & $8.2 \%$ \\
\hline RUS & 33.9 & 43.1 & 28.7 & 69.8 & 74.1 & 60.2 & 110.8 & 57.6 & $226.3 \%$ & $33.5 \%$ \\
\hline TWN & 25.3 & 9.5 & 26.6 & 9.2 & 28.1 & 11.8 & 26.0 & 14.4 & $2.6 \%$ & $51.0 \%$ \\
\hline TUR & 13.5 & 14.8 & 19.2 & 14.9 & 24.0 & 16.7 & 36.1 & 15.1 & $167.5 \%$ & $1.9 \%$ \\
\hline USA & 256.2 & 189.5 & 364.5 & 165.4 & 443.6 & 169.6 & 419.6 & 249.2 & $63.8 \%$ & $31.5 \%$ \\
\hline RoW & 144.9 & 473.8 & 162.5 & 565.7 & 258.3 & 842.7 & 426.7 & 952.4 & $194.5 \%$ & $101.0 \%$ \\
\hline WORLD & $1,297.9$ & $1,297.9$ & $1,482.8$ & $1,482.8$ & $1,995.9$ & $1,995.9$ & $2,467.8$ & $2,467.8$ & $90.1 \%$ & $90.1 \%$ \\
\hline
\end{tabular}

AUS: Australia, AUT: Austria, BEL: Belgium, BGR: Bulgaria, BRA: Brazil, CAN: Canada, CHN: China, CYP: Cyprus, CZE: Czech Republic, DEU: Germany, DNK: Denmark, ESP: Spain, EST: Estonia, FIN: Finland, FRA: France, GBR: United Kingdom, GRC: Greece, HUN: Hungary, IDN: Indonesia, IND: India, IRL: Ireland, ITA: Italy, JPN: Japan, KOR: South Korea, LTU: Lithuania, LUX: Luxembourg, LVA: Latvia, MEX: Mexico, MLT: Malta, NLD: Netherlands, POL: Poland, PRT: Portugal, ROM: Romania, ROW: Rest of the World, RUS: Russia, SVK: Slovak Republic, SVN: Slovenia, SWE: Sweden, TUR: Turkey, TWN: Taiwan, USA: United States.

\footnotetext{
${ }^{6}$ It is calculated as the sum of the import-export activities of the EU-27 Member States. It includes intra-EU trade.

${ }^{7}$ It is calculated as the import-export activities that took place between the EU-27 and the other countries, without considering the import-export activities that took place within the EU-27.
} 
Table A.7: Water trade flows by main partner countries $(2008)\left(\mathrm{km}^{3}\right)$

\begin{tabular}{|c|c|c|c|c|c|c|c|c|c|c|c|c|c|c|c|c|}
\hline & AUS & BRA & CAN & CHN & IND & IDN & JPN & KOR & MEX & RUS & TWN & TUR & USA & RoW & EU-27 & Total Export \\
\hline AUS & 0.0 & 0.2 & 0.7 & 6.3 & 0.7 & 2.6 & 6.5 & 1.9 & 0.3 & 0.6 & 0.8 & 0.1 & 3.8 & 15.2 & 5.0 & 44.8 \\
\hline BRA & 1.0 & 0.0 & 2.7 & 27.7 & 1.1 & 1.2 & 8.0 & 3.2 & 1.2 & 6.0 & 0.8 & 1.3 & 15.4 & 63.1 & 54.7 & 187.7 \\
\hline CAN & 0.7 & 1.1 & 0.0 & 7.0 & 1.6 & 1.5 & 13.1 & 1.3 & 5.8 & 1.0 & 0.6 & 1.1 & 55.3 & 18.8 & 14.5 & 123.4 \\
\hline $\mathrm{CHN}$ & 10.2 & 5.5 & 15.6 & 0.0 & 11.2 & 6.3 & 41.7 & 15.6 & 5.8 & 18.1 & 4.1 & 4.2 & 97.6 & 124.6 & 108.8 & 469.4 \\
\hline IND & 2.0 & 1.4 & 3.1 & 11.6 & 0.0 & 2.6 & 4.5 & 2.4 & 1.4 & 3.8 & 2.1 & 1.6 & 28.9 & 49.8 & 40.7 & 155.8 \\
\hline IDN & 1.4 & 0.9 & 1.0 & 8.3 & 5.0 & 0.0 & 5.9 & 1.5 & 0.5 & 1.0 & 0.5 & 0.7 & 9.2 & 23.4 & 15.1 & 74.4 \\
\hline JPN & 0.1 & 0.1 & 0.1 & 1.1 & 0.1 & 0.1 & 0.0 & 0.3 & 0.1 & 0.2 & 0.3 & 0.0 & 1.1 & 1.4 & 0.9 & 5.7 \\
\hline KOR & 0.0 & 0.0 & 0.0 & 0.5 & 0.0 & 0.0 & 0.4 & 0.0 & 0.0 & 0.1 & 0.0 & 0.0 & 0.4 & 0.7 & 0.4 & 2.7 \\
\hline MEX & 0.1 & 0.1 & 1.4 & 0.5 & 0.1 & 0.0 & 0.8 & 0.1 & 0.0 & 0.1 & 0.1 & 0.1 & 14.2 & 3.3 & 2.1 & 23.0 \\
\hline RUS & 0.4 & 0.7 & 0.5 & 7.5 & 1.0 & 0.4 & 5.6 & 2.4 & 0.4 & 0.0 & 0.2 & 2.1 & 4.8 & 13.8 & 17.8 & 57.6 \\
\hline TWN & 0.2 & 0.1 & 0.3 & 2.1 & 0.1 & 0.1 & 2.8 & 0.3 & 0.1 & 0.3 & 0.0 & 0.1 & 4.2 & 2.4 & 1.3 & 14.4 \\
\hline TUR & 0.1 & 0.1 & 0.2 & 0.2 & 0.1 & 0.1 & 0.3 & 0.1 & 0.1 & 1.0 & 0.0 & 0.0 & 0.9 & 4.7 & 7.2 & 15.1 \\
\hline USA & 2.0 & 2.2 & 24.8 & 30.2 & 2.1 & 3.5 & 40.4 & 11.6 & 30.7 & 3.5 & 6.1 & 2.8 & 0.0 & 52.9 & 36.4 & 249.2 \\
\hline RoW & 14.0 & 22.1 & 21.2 & 132.6 & 25.7 & 11.3 & 70.4 & 22.4 & 13.6 & 69.1 & 9.7 & 17.9 & 172.4 & 0.0 & 350.0 & 952.4 \\
\hline EU-27 & 1.2 & 1.4 & 2.0 & 5.5 & 1.0 & 0.5 & 3.7 & 1.2 & 1.0 & 5.9 & 0.6 & 4.0 & 11.4 & 52.7 & 0.0 & 92.3 \\
\hline $\begin{array}{l}\text { Total } \\
\text { Import }\end{array}$ & 33.5 & 35.8 & 73.7 & 241.0 & 49.9 & 30.4 & 204.1 & 64.2 & 61.1 & 110.8 & 26.0 & 36.1 & 419.6 & 426.7 & 655.0 & $2,467.8$ \\
\hline
\end{tabular}

AUS: Australia; BRA: Brazil; CAN: Canada; CHN: China; EU-27: European Union; IDN: Indonesia; IND: India; IDN: Indonesia; JPN: Japan; KOR: South Korea; MEX: Mexico; RoW: Rest of the World; RUS: Russia; TWN: Taiwan; TUR: Turkey; USA: United States. 